\title{
Human Pluripotent Stem-Cell-Derived Models as a Missing Link in Drug Discovery and Development
}

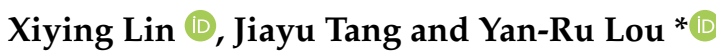 \\ Department of Clinical Pharmacy and Drug Administration, School of Pharmacy, Fudan University, \\ Shanghai 201203, China; 20211030094@fudan.edu.cn (X.L.); 15307130212@fudan.edu.cn (J.T.) \\ * Correspondence: yanru_lou@fudan.edu.cn
}

check for updates

Citation: Lin, X.; Tang, J.; Lou, Y.-R. Human Pluripotent Stem-Cell-Derived Models as a Missing Link in Drug Discovery and Development. Pharmaceuticals 2021, 14, 525. https: / / doi.org/10.3390/ ph14060525

Academic Editor: Saima Imran

Received: 3 May 2021

Accepted: 27 May 2021

Published: 30 May 2021

Publisher's Note: MDPI stays neutral with regard to jurisdictional claims in published maps and institutional affiliations.

Copyright: (c) 2021 by the authors. Licensee MDPI, Basel, Switzerland. This article is an open access article distributed under the terms and conditions of the Creative Commons Attribution (CC BY) license (https:// creativecommons.org/licenses/by/ $4.0 /)$.
Abstract: Human pluripotent stem cells (hPSCs), including human embryonic stem cells (hESCs) and human-induced pluripotent stem cells (hiPSCs), have the potential to accelerate the drug discovery and development process. In this review, by analyzing each stage of the drug discovery and development process, we identified the active role of hPSC-derived in vitro models in phenotypic screening, target-based screening, target validation, toxicology evaluation, precision medicine, clinical trial in a dish, and post-clinical studies. Patient-derived or genome-edited PSCs can generate valid in vitro models for dissecting disease mechanisms, discovering novel drug targets, screening drug candidates, and preclinically and post-clinically evaluating drug safety and efficacy. With the advances in modern biotechnologies and developmental biology, hPSC-derived in vitro models will hopefully improve the cost-effectiveness and the success rate of drug discovery and development.

Keywords: human pluripotent stem cells; human embryonic stem cells; human-induced pluripotent stem cells; drug discovery; drug development

\section{Brief Introduction to Human Pluripotent Stem Cells (hPSCs) and Their Applications}

Human pluripotent stem cells (hPSCs), including human embryonic stem cells (hESCs) and human induced pluripotent stem cells (hiPSCs), are cells with the ability to self-renew and to develop into all cell types in a human adult body [1]. hESCs come from the blastocyst, which is a developing embryo 5-6 days after fertilization. As for hiPSCs, they are derived from reprogrammed somatic cells with ectopic expression of pluripotency factors, like OSKM (OCT4/SOX2/KLF4/C-MYC) [2].

Grown in vitro, hPSCs show the potential to generate all lineages of the embryo in vivo and can differentiate into all types of somatic cells in vitro, becoming a popular and valuable cellular source for the treatment of many degenerative diseases, including Parkinson's disease (PD), Alzheimer's disease (AD), and age-related macular degeneration (AMD) [3], as well as injuries to tissues lacking regeneration capability such as ischemic heart failure [4], diabetes, and spinal cord injuries [5]. Moreover, hPSCs can be used for tissue and organ reconstruction in vitro. A typical approach is to culture isolated hPSCs on a supportive matrix to provide a three-dimensional (3D) growth environment for stem cells. At the same time, based on the understanding of organ development in vivo, specific cytokines and growth factors are added to the matrix to induce differentiation into specific organs. In such cultures, stem cells differentiate and self-assemble to form organ-like structures like organs or tissues in the body, which are called organoids. An organoid [6,7] is a 3D cell model constructed in vitro by stem cells or progenitors grown in extracellular matrix hydrogels or in biomaterial-free 3D conditions according to the physiological structure of the organ. It can mimic the cell type, structure, and function of the corresponding organ. Depending on the study, these cells can be derived from tissues of healthy and diseased people and from hPSCs. If organoids can be applied to organ transplantation, it will largely solve the problem of the current organ shortage and organ transplantation. 
Besides their in vivo applications, hPSCs have the potential to accelerate the drug discovery and development process. By utilizing hPSC technology, models for many complex diseases can be established, which can take part in several stages of the drug discovery and development pipeline like lead discovery, in vitro studies, and post-clinical studies.

With the recognition of the value of hPSC-derived cell models, researchers have written many reviews on this topic. For example, Rowe and Daley [8] wrote a review on the use of iPSC-derived organoids in disease modeling, particularly emphasizing hostpathogen interactions and human-animal chimaeras. By analyzing a number of key central nervous system (CNS) disorders, Silva and Haggarty [9] presented phenotypic analysis of hPSC-derived models and their applications in drug screening. A more recent review by Garcia-Leon et al. [10] focused on drug screening in AD by using hiPSC-derived neurons and their related cell types. Contrary to focusing on a particular application or disease, we present the potential of hPSC-derived models during the whole process of drug discovery and development.

\section{Overview of Current Drug Discovery and Development}

The drug discovery pipeline involves several stages. The first is to use a certain target, a phenotypic screening method or a target-based screening method, to pick up one or more candidate molecules, which are also called lead compounds or leads. Lead compounds next go into medicinal chemistry programs for structure modification to enhance specificity, efficacy, and stability. During this stage, the effect of compounds is mainly tested in vitro using immortalized cells and/or primary cells. Then, the most effective compounds are directed into the stage of in vivo animal studies. Their toxicity, optimal dose, and delivery route need to be studied [11]. After being synthesized, a compound must be rigorously tested in preclinical studies to make sure that the drug under study is of sufficient efficacy, together with minimal side effects [12].

Lead discovery in target-based and phenotypic screening are usually based on immortalized cells, and evaluating efficacy and safety in preclinical trials are generally based on immortalized cells, primary cells, and animal models. Unfortunately, there are significant problems with each of these models. For example, there exist significant differences between cardiac electrophysiology in mice and humans, which can be indicated by heart rate-a human's heart rate is generally around 70 beats per minute $(\mathrm{bpm})$, whereas that of a mouse is about $600 \mathrm{bpm}$ [13]. Compared to animal models, primary cells show human physiology and pathology in a more direct way, whereas the latter are difficult to obtain and maintain. For instance, enough human coronary endothelial cells, derived from human coronary arteries, are difficult to get for expansion because of the invasive procedure. Consequently, coronary endothelial cells usually have to be pooled, which makes it impossible to ascertain individual differences [14]. Therefore, a novel model is urgently needed to make drug development procedures more efficient with lower costs and higher accuracy.

As an alternative to animal models and primary cells, hPSC technology has caused a radical change in the field of drug discovery and clinical trials. Allowing for generating disease- and patient-specific functional somatic cells in a large scale, hPSC technology can avoid many problems that usually accompany animal and primary cell models.

Following success in preclinical studies, the selected compound enters the stage of clinical trials, which include phases I, II, and III. In phase I trials, the safety of the compound in the human body is tested, whereas in phases II and III, the efficacy and safety are tested in a larger number of patients. After accomplishing phase III, the candidate drug must seek permission from relevant regulatory agencies to enter the market [11].

Drug discovery and development is inherently risky. A major challenge in drug development is the high attrition rate before entering the market. According to research by DiMasi et al. [15], less than $11 \%$ of new pharmaceutical agents that entered clinical studies finally obtained marketing approval. The estimated clinical approval success rates for selforiginated drugs varied noticeably by therapeutic class. The estimated approval success rates of CNS, cardiovascular, gastrointestinal/metabolism, and respiratory categories are 
relatively low at $8 \%, 9 \%, 9 \%$, and $10 \%$, respectively, whereas that of systemic anti-infectives is relatively high at $24 \%$ [16]. And the estimated average out-of-pocket cost per new drug is USD 403 million [15].

Another challenge in drug development is drug withdrawal from the market, which often results from a safety issue. For example, the COX-2 inhibitor rofecoxib was withdrawn because of severe vascular toxicity, causing huge financial losses to Merck. An analysis on drug withdrawal during 1990-2010 has found that 133 drugs were withdrawn because of safety reasons, including hepatotoxicity, cardiotoxicity, nephrotoxicity, and hypersensitivity [17]. Another larger study has identified 462 drugs that were withdrawn from the market during 1953-2013 because of adverse drug reactions, among which hepatotoxicity was the most common reason [18].

To reduce the loss from high attrition and withdrawal in drug development, the key point is to reduce failure in the stage of clinical trials. To achieve the goal, promoting efficiency and accuracy of drug screening and eliminating potential toxic and/or ineffective compounds before entering clinical trials are urgently needed. In the stages of drug discovery and preclinical studies, there are many processes in which hPSCs can play an active role (Figure 1). In the following sections, we reviewed the role of hPSC-derived models in disease modeling, target discovery, drug screening, and toxicity evaluation (Figure 2). Moreover, cells can be generated from multiple patients to carry out "clinical trials in a dish" $[19,20]$.

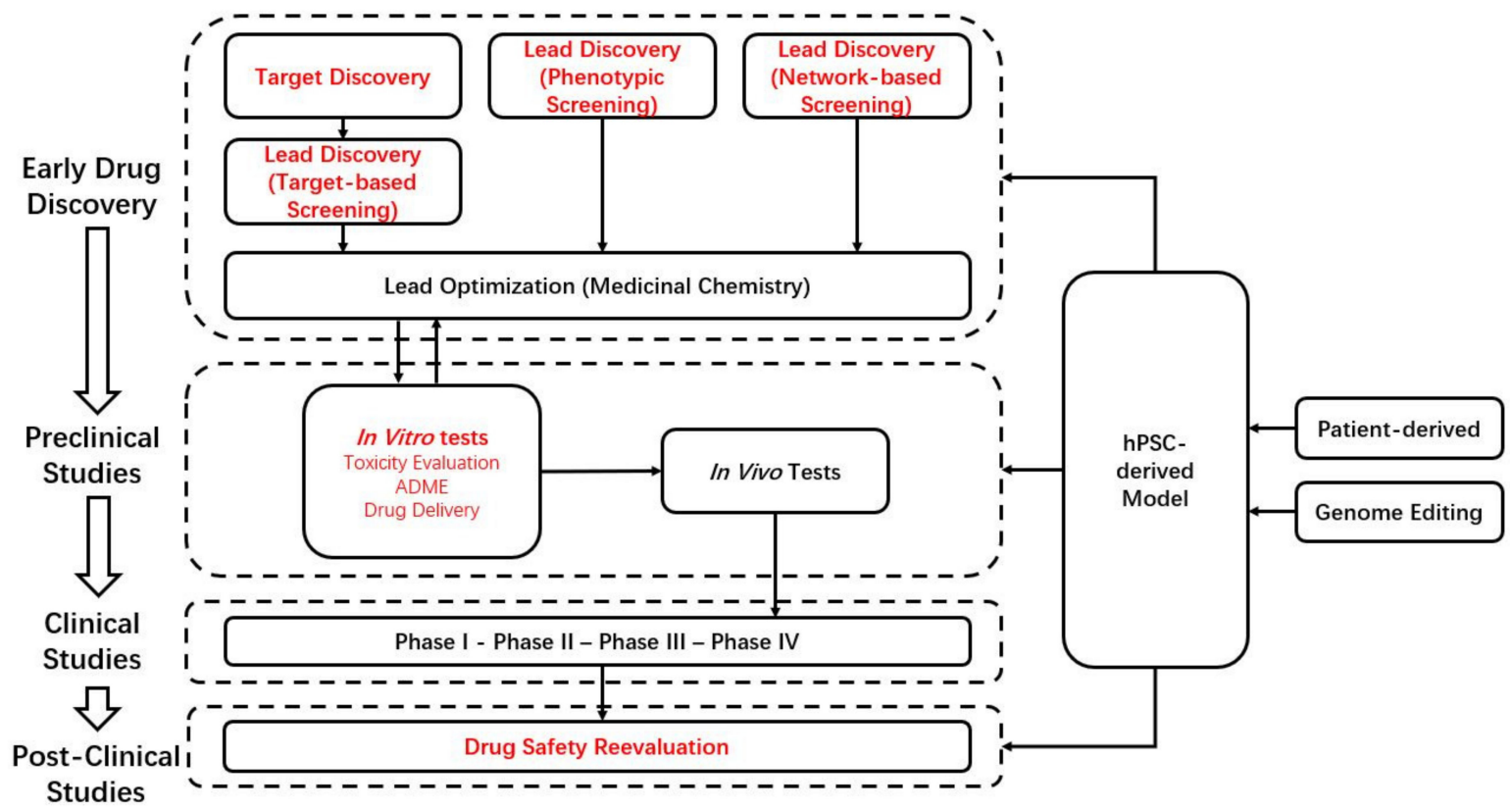

Figure 1. The workflow of drug discovery and development. Words in red font are stages that may involve hPSCs. ADME: absorption, distribution, metabolism, and excretion. 


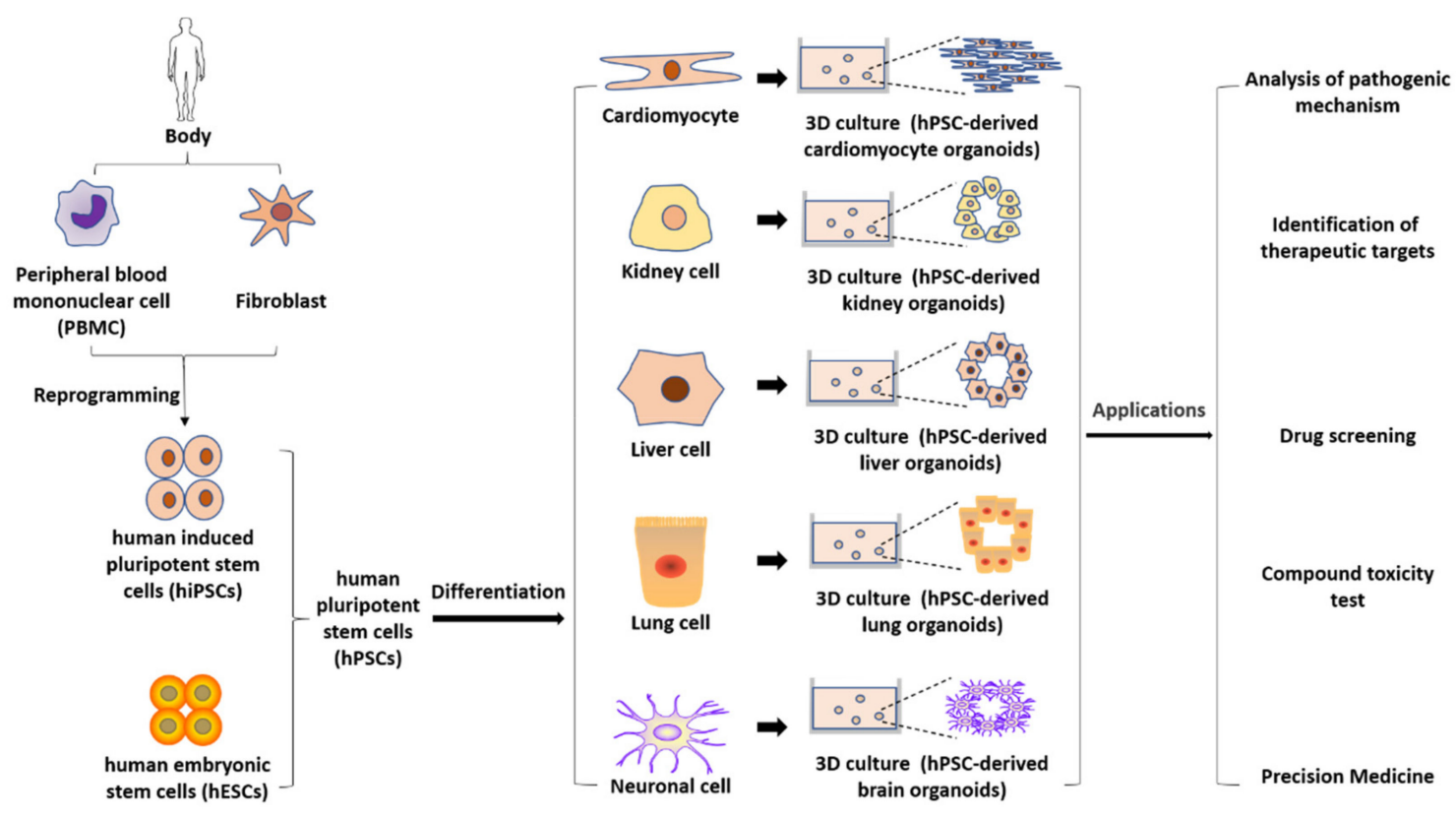

Figure 2. Types and possible applications of hPSC-derived models.

\section{3. hPSC-Derived Disease Models}

Disease models are useful for probing the etiology and pathophysiology of a disease and are critical for efficient discovery and development of novel therapeutics. Disease models within the current pharmaceutical industry rely heavily on animals (like spontaneously hypertensive rats [21], the rat pilocarpine model of epilepsy [22], chromosome-engineered mouse models of Down syndrome [23]) or immortalized cell lines (like HBV genomeintegrated stable cells, HepG2.2.15 as an HBV infection model [24], lymphoblastoid cell lines as a mitochondrial disease model [25], the neuroblastoma SH-SY5Y cell line as a PD model [26]), which are usually from human tumors. Compared with primary cells, tissue slices, or intact organs, these foresaid models manifest limited biological relevance, but the former also have shortcomings. For example, primary human hepatocytes (PHHs) are the current gold standard for in vitro liver cell culture models, but the limited supply and difficult logistics of PHHs make it difficult to use PHHs in a larger scale. In addition, PHHs are found to lose the hepatocellular phenotype progressively when cultured over extended periods. Moreover, the isolation procedure causes interindividual differences and cell alterations, leading to some result variations in experiments [27].

With similar features to primary cell types and higher accessibility $[28,29]$ in combination with technologies such as 3D cell cultures, organoid technology, and microfabrication, hPSCderived functional somatic cells are promising in offering more accurate disease models.

\subsection{Models for the Study of Genetic Disorders}

\subsubsection{Patient-Derived hPSC Models}

The discovery of patient-derived hiPSCs has produced various types of cells that can be used as in vitro models for many tricky diseases for which there were previously none. Now there have been hiPSC models for many genetic disorders, including hepatological diseases, hematological and immunological diseases, and cardiac diseases.

Systemic lupus erythematosus (SLE) is a kind of chronic inflammatory autoimmune disease that may impact on any part of the body [30]. According to previous studies, SLE shows significant familial aggregation, and the incidence was consistently higher in homozygotes $(24 \%)$ than in heterozygotes ( $2 \%$ ) [31]. The pathogenesis involves dysfunction of both specific and nonspecific immunity [32], but the etiology remains unclear. For SLE, there is still no effective cure [33], and the current immunosuppressive therapy is of high cost, with an unignorable risk of side effects like various infections and cardiovascular disease [34]. Within 
the SLE patient group, the phenotype and stage of progression are various [35,36]; therefore, personalized treatment is needed for a better effect. By utilizing mononuclear cells of SLE patients, Li et al. [37] generated SLE patient-derived hiPSCs successfully, which offers a tool for exploration of the SLE disease mechanism and drug discovery.

Polycystic kidney disease (PKD), a common cause of end-stage renal disease, is a lethal single-gene disorder [38]. The difficulty to recapitulate kidney structures correctly in vitro is a hurdle in the further study of the PKD mechanism and drug development. Utilizing polydimethylsiloxane scaffolds and hiPSCs derived from a PKD patient with a PAX2 mutation, Benedetti et al. [39] generated ureteric bud-like 3D tubules, paving the way for studying the PKD mechanism and developing personalized medicine.

Neurofibromatosis type 1 (NF1), a tumor predisposition syndrome, is a common human genetic disorder affecting the nervous system. It is caused by mutations in the NF1 gene, leading to neurofibromas, which are peripheral nerve sheath tumors derived from Schwann cells. In order to study neurofibroma pathogenesis, Mo et al. [40] generated Schwannian lineage cells (SLCs) from a set of NF1 mutant patient-derived hiPSCs. They implanted hiPSC-derived SLCs into mouse sciatic nerve and discovered that NF1-null ones successfully formed authentic neurofibromas in the mouse nerve system, setting up a humanized neurofibroma model.

In summary, patient-derived hiPSC disease models are useful tools to discover effective drug treatments for diseases without well-understood mechanisms. These models can be further combined with phenotypic screening (see Section 4.2) to identify effective treatments. For disease mechanism and pharmacology studies, a drawback of patient-derived hiPSC disease models is the lack of true isogenic control, which makes data interpretation challenging.

\subsubsection{Genome-Edited hPSC Models}

As an emerging technology, genome editing using engineered nucleases has been applied to modify target genes in virtually all types of cells. Nucleases used for targeted genome editing include transcription activator-like effector nucleases (TALENs) [41,42], zinc finger nucleases (ZFNs) [43], and clustered regularly interspaced short palindromic repeat (CRISPR)-associated nuclease Cas9 [44]. In 2012, Jinek et al. [45] first demonstrated that CRISPR-Cas9 could be used to specifically cleave target DNA and suggested its potential as a gene editing tool for eukaryotes. Within several months, CRISPR-Cas9 was proven to be capable to edit the human genome [46]. By now genome editing has been applied in hPSCs. We recently developed an improved CRISPR method based on Cas 9 mRNA to target genes at highly condensed chromatin regions and achieved up to a $76 \%$ biallelic targeting efficiency in hPSCs [47]. Being able to be used for direct correction or insertion of interested genetic mutations in hPSCs, genome editing with programmable nucleases represents an effective tool for fundamental and preclinical research, including developing disease models $[48,49]$.

Retinitis pigmentosa (RP) is a common type of hereditary retinal dystrophy, which involves primarily retinal cells and retinal pigment epithelial cells, ultimately resulting in blindness [50]. A severe form of X-linked retinitis pigmentosa (XLRP) is caused by RP2 mutations. In animal models of RP2 XLRP, the severe phenotype has failed to be recapitulated, so there is an urgent need for a proper model. Using the CRISPR/Cas9 technique, Lane et al. [51] knocked out RP2 gene in hiPSCs. Then, RP2-knockout (RP2-KO) hiPSCs, the non-edited isogenic control, and RP2 patient-derived hiPSCs were differentiated into $3 \mathrm{D}$ retinal organoids (ROs). Noticeably, rod photoreceptor cells in RP2 patient-derived and RP2-KO ROs exhibited a spike in cell death by day 150 of culture. Subsequently, the thickness of the organoid outer nuclear layer (ONL) was found to be less at day 180 . To rescue the degeneration phenotype, adeno-associated virus was applied to mediate gene augmentation with human RP2 and was found to be effective in stopping ONL getting thinner as well as in recovering rhodopsin expression. In summary, this research set up a 3D model with hiPSC-derived ROs. Using the model, the phenotype of RP2 XLRP can be successfully recapitulated, and potential treatment can be tested. 
Amyotrophic lateral sclerosis (ALS) is a neurodegenerative disorder that features progressive degeneration of motor neurons (MNs), which causes symptoms like muscle weakness, atrophy, and paralysis and leads to respiratory failure and death in the late stage [52]. Some familial ALS cases are caused by mutations in the superoxide dismutase 1 (SOD1) gene that encodes SOD1, an antioxidant enzyme-scavenging superoxide radical; but, the mechanisms remain unclear [53]. To understand the naturally occurring pathology of ALS and how the SOD1 mutation affects MNs, utilizing a CRISPR/Cas9 genome editing system on hiPSCs, Kim et al. [54] generated hiPSC-derived MNs harboring a knocked-in SOD1-G93A missense mutation. In this research, the wild-type MN cell line served as an isogenic control, while MNs generated from a patient-derived hiPSC line harboring another form of SOD1 mutation served as a positive control. In the cell bodies of MNs with either a G93A or A4V mutation, misfolded and aggregated forms of SOD1 were accumulated, including axons. Additionally, they showed distinctive axonal pathologies including larger and shorter axons and less branch points. In addition, structural and molecular abnormalities were identified in presynaptic and postsynaptic structures. Furthermore, aberrant neurotransmission was identified in mutant MNs. All these disease phenotypes relevant to ALS indicate that genome-edited hiPSCs utilizing CRISPR/Cas9 technology and MNs derived from them, together with their proper control cells, are important to the modeling of ALS and the study of disease mechanisms in human ALS.

KCNQ1 and KCNH2, which encode potassium channels, are important genes leading to long QT (the time from the start of the $Q$ wave to the end of $T$ wave on an electrocardiogram) syndrome (LQTS) [55]. Wang et al. [56] inserted the ion channel genes KCNQ1 and $\mathrm{KCNH} 2$ into the genome of hPSCs by the ZFN technique. The edited hiPSC-derived cardiomyocytes (hiPSC-CMs) showed characteristic LQTs and a significantly longer action potential duration (APD) than unedited cardiomyocytes. At the same time, APD was significantly shortened when hiPSC-CM was treated with nifedipine (an L-type calcium channel blocker) or pinanardil (a KATP channel opener). The results showed that the gene-edited hiPSC-CMs successfully constructed the LQTS model in vitro and provided materials for studying the mechanism of LQTS and drug screening.

In summary, genome editing technology can generate true isogenic controls with identical genetic background except the gene of interest, which overcomes the drawback of patient-derived hPSC models. However, the knowledge of disease-causing genetic information is a prerequisite for genome editing.

\subsection{Models for the Study of Acquired Diseases}

Neurodegenerative diseases are a kind of serious acquired disease, which include AD, $\mathrm{PD}$, multiple sclerosis, etc. [57]. They feature a chronic and progressive deterioration of neuronal function, leading to cognitive impairment, impaired motor function, memory loss, and sensory and emotional changes in patients. While studying animal models of neurodegenerative diseases, Dawson et al. [58] proposed that many neurodegenerative diseases share the same pathological manifestations, including abnormal accumulation of toxic aggregates [59], oxidative stress, mitochondrial dysfunction [60], defective axon transport [61], and chronic inflammation [62], which eventually lead to neurodegenerative diseases. Because of the complex pathogenesis of neurodegenerative diseases, currently, there is no specific drug for neurodegenerative diseases in clinical practice, only symptomatic drugs that can relieve the symptoms. Modeling of neurodegenerative diseases is also a challenge. While animal models of neurodegenerative diseases have emerged [58], they require the use of many animals and a large amount of time, and the differences between species also make animal models have certain limitations. With the development of science and technology, hPSCs have brought hope to people. Somatic cells were extracted from patients with neurodegenerative diseases and reprogramed to hiPSCs by pluripotent factors. Different differentiation factors then induce differentiation into specific nerve cell types, including dopaminergic neurons, cholinergic neurons, astrocytes [63], and so on. 
Using these nerve cells to construct models of neurodegenerative diseases can greatly solve the problems existing in animal models.

The histopathological features of AD are the aggregation of $\beta$-amyloid peptide $(\mathrm{A} \beta)$ and the protein tau tangled together to form plaques [64]. Currently, rodent models of $\mathrm{AD}$ are widely used in clinical practice, but there are some differences between rodent models and human models, and a human model is the gold standard for studying AD. Therefore, the construction of a human $\mathrm{AD}$ model has become the research direction of many scholars. The development of hiPSC technology has made it possible to model AD in vitro. By using CRISPR-FokI technology, García-León et al. [65] created three mutations (N279K, P301L, and E10 + 16) in the 10th exon and adjacent region of the MAPT gene, which encodes tau. These mutations caused tau aggregation in hiPSC-derived neurons and glial cells accompanied with a series of neurodegenerative changes, such as inflammation, oxidative stress, and electrophysiological alterations. Using this model, the authors were able to study AD in vitro. hiPSC-based systems and genome editing tools can help to figure out the mechanism of neurodegenerative diseases and promote the research of $\mathrm{AD}$ and other neurodegenerative diseases.

PD is caused by the loss of dopaminergic neurons in the substantia nigra striatum system. Transplantation of dopaminergic neurons has become one of the approaches to treat PD. Clinically, drug therapy is mainly used because of its low cost, high patient compliance, and its being non-invasive. The emergence of hPSCs has made cell therapy become a research hotspot. Cell transplantation therapy has been proven to be safe and effective. Dopaminergic neurons derived from autologous hiPSCs were transplanted into non-human primates. They survived for two years without immunosuppression and the animal's nervous system recovered [66]. In 2016, International Stem Cell Corporation initiated the first approved clinical trial of hiPSCs to treat patients with PD in Melbourne, Australia [67]. In the future, the combination of cell therapy and drug therapy may become one of the important methods to treat PD.

Currently, many cell types derived from hiPSCs have molecular features like fetal cells based on transcriptomic, structural, or functional studies, and the in vitro differentiation of hiPSCs can faithfully mimic in vivo embryo and fetal development [68-70], which makes this model particularly useful in studying disease development at the prenatal stage. However, for those acquired diseases that develop with age, hiPSC-derived cell models may have less potential. Attempts have been made to improve in vitro maturation. For example, Burke et al. [71] co-cultured hiPSC-derived neuronal cells with astrocytes and obtained $48 \%$ of transcripts representing mature cortical neurons. Kolanowski et al. [72] cultured hiPSC-derived cardiomyocytes in a microfluidic device that provided pulsatile hemodynamic signals to the cells. This method increased the alignment and mitochondrial functions of the cells.

\section{4. hPSC-Derived Models in Drug Discovery and Development}

\subsection{Target Discovery}

A drug target can be defined as "a molecule in the body, usually a protein that is intrinsically associated with a particular disease process and that could be addressed by a drug to produce a desired therapeutic effect" [73]. Discovering a proper therapeutic target is the basis of the classic drug development pipeline. Models derived from hPSCs, amenable to scale up and like primary cell types, are of potential use in discovering therapeutic targets in fundamental research.

A major cause of mitochondrial diseases is mutations in mitochondrial DNA (mtDNA). The cells with disease-related mutations in mtDNA present a series of phenotypes like reduced respiration and increased lactification. hiPSCs derived from patients with mitochondrial disease, with high proportions of mutated mtDNA, display maturation defects. Kobayashi et al. [74] discovered that tryptolinamide (TLAM), a small-molecule compound, activates the function of mitochondria in hybrid cells generated from anucleate cytoplasm of patientderived cells and in fibroblasts differentiated from patient-derived hiPSCs. They found that 
TLAM is an inhibitor of phosphofructokinase-1 (PFK1). Increasing the level of AMP-activated protein kinase-mediated acetyl-CoA carboxylase phosphorylation, TLAM promotes oxidative phosphorylation and shifts energy metabolism from glycolysis to mitochondrial respiration. Moreover, TLAM rescues the phenotype of patient-derived hiPSCs, suggesting that PFK1 is of potential to become a disease-modifying target for mitochondrial diseases.

$\mathrm{N}$-methyl-D-ionic glutamate receptors (NMDARs) are neuron-expressing ionotropic glutamate receptors. Studies in various animal models have found that Src family kinases are involved in brain development and activities by regulating the function of NMDARs. Data from human neurons are scarce. By using hiPSC-derived neurons, Zhang et al. [75] found that Fyn, a member of Src family kinases, promoted the function of GluN2B subunit-containing NMDARs, indicating that Fyn could be a drug target to regulate neuron functions.

In summary, hPSC-derived models help to identify therapeutic targets, paving the way for subsequent research for developing effective therapies.

\subsection{Phenotypic Screening}

Phenotypic screening is a strategy of lead discovery, which is based on measurable phenotypic endpoints from cells or organisms without having prior knowledge of the drug target [76]. Phenotypic screening offers an unbiased approach to "chemically interrogate the proteome in its pathophysiologically-relevant environment" and promote opportunities to uncover the true disease mechanisms and to identify potential therapeutic drugs [77]. In recent years, phenotypic screening is becoming popular for identifying disease-modifying bioactive compounds [78], particularly for diseases where critical therapeutic targets have been hard to identify in other ways [79]. Thus, phenotypic screening may contribute to reducing high attrition rates in drug development, especially the failures in phase II, which usually result from insufficient efficacy. hPSC models are promising in providing platforms for phenotypic screening to identify candidate drugs for many intractable diseases.

Tuberculosis (TB), caused by Mycobacterium tuberculosis (Mtb), is a major infectious disease over the world [80]. Standard therapy for drug-sensitive TB involves core antibiotics including isoniazid, rifampicin, pyrazinamide, and ethambutol. However, TB treatment is faced with the challenge of multidrug-resistance (MDR) and extensive drugresistance (XDR), so there arises an urgent need for novel anti-TB drugs. The entire genome sequence of Mtb was described in 1998, which facilitated identifying new drug targets and developing drug screening based on new targets [81]. However, not many targets have been identified so far, and for quite a few vital ones, there are no specific inhibitors of clinical value. There have been no clinically effective anti-TB drugs discovered adopting target-based strategy [82]. To overcome the MDR problem and to move beyond the strategy based on classic targets, phenotypic screening has been an acceptable alternative.

Han et al. [83] developed a modified protocol for using hESCs to generate homogeneous populations of macrophage-like cells (iMACs), which showed similar transcriptomic profiles and had characteristic immunological features of classical macrophages. Moreover, iMAC production could be scaled up. Using iMACs infected with Mtb H37Rv-GFP9 (a mycobacterial laboratory strain, modified to express GFP), they performed a high-throughput phenotypic screening against intracellular Mtb, involving a library of 3716 compounds. In the primary screening, there were 120 hits identified, then a secondary screening was performed by dose-intracellular and -extracellular Mtb assays. Finally, a new anti-Mtb compound named 10-DEBC was identified, which showed activity against drug-resistant Mtb strains as well.

For ALS, there has been no effective treatment or common therapeutic target. In a study conducted by Imamura et al. [84], motor neurons differentiated from ALS patientderived hiPSCs were used for phenotypic screening. In the screening, survival of motor neurons differentiated from ALS patient-derived hiPSCs was used as an endpoint. They screened existing drugs and found that $\mathrm{Src} / \mathrm{c}-\mathrm{Abl}$ kinases inhibitors promoted autophagy and rescued ALS motor neurons from degeneration. Bosutinib, one of Src/c-Abl kinases' inhibitors, was effective for increasing the survival of ALS patient-derived motor neurons. 


\subsection{Network-Based Screening}

Traditional small-molecule screening approaches aiming at identifying therapeutic candidates generally search for molecules involving merely one to several outputs, which limits the discovery of drugs with actual therapeutic effects. In 2007, A.L. Hopkins pioneered the concept of "network pharmacology" [85]. The concept is based on the theories of systems biology, genomics, proteomics, polypharmacology, etc. and uses technologies such as histology, high-throughput screening, network visualization, and network analysis to reveal the complex biological network relationships among drugs, genes, targets, and diseases, based on which the pharmacological mechanisms of drugs are analyzed and predicted [86]. Based on network pharmacology, a network-based screening strategy provides a holistic perspective of disease mechanisms, offering an unbiased approach to assess a drug's therapeutic effect and to identify disease-modifying drugs. Recently, hPSC-derived models have been used in the construction of gene networks in network-based screening.

$\mathrm{AD}$ is a common cause of elderly dementia, affecting over 40 million patients all around the world [87]. Symptoms of AD include loss of memory and decline in cognitive functions, resulting from neuronal impairment and death, which is accompanied by brain inflammation [88]. AD is a multifactorial disease, which involves several regulatory processes, like lipid metabolism, vesicle trafficking, and endocytosis [89,90]. Based on different onset mechanisms, several subtypes of AD have been defined [91].

Considering the diversity of risk factors and onset mechanisms, it is difficult to discover a disease-modifying target for all $\mathrm{AD}$ patients if the screening strategy focuses on a single pathway. Thus, there arises a need for an approach that takes all existing genetic factors and relevant regulatory pathways into consideration to search for an optimal therapeutic target [92].

To develop effective drugs for AD, Park et al. [93] set up a network-based drug-screening platform combining mathematical modeling and hiPSC technology. They constructed a mathematical $\mathrm{AD}$ signaling model integrating relevant pathways validated with iCOs, which are cerebral organoids differentiated from hiPSCs (including patient-derived and CRISPRCas9-edited hiPSCs) and built a high-content screening system using 1300 organoids from 11 participants, providing a platform for drug assessment and precision medicine.

By combining machine-learning and hiPSC technologies, Theodoris et al. [94] developed an approach to search therapeutic candidates for aortic valve (AV) disease. It is reported that heterozygous loss-of-function NOTCH1 (N1, a transmembrane receptor that functions as a transcriptional regulator) mutations cause $\mathrm{AV}$ stenosis and calcific $\mathrm{AV}$ disease [95]. Utilizing machine learning, they drew a map of gene networks dysregulated by N1 haploinsufficiency with hiPSC-derived endothelial cells and identified an efficacious therapeutic candidate that can correct the network dysregulation, XCT790. Moreover, the effectiveness of XCT790 was generalized to primary AV cells from over $20 \mathrm{AV}$ patients and a mouse model.

\subsection{Models for the Study of Disease Mechanisms}

Muscular dystrophies (MD) comprise a group of hereditary and progressive muscle diseases that result from a number of different gene mutations, of which terminal pathology often represents muscle necrosis and replacement by fibrotic or fatty tissues. Lacking appropriate models, the studies of MDs are limited. Being able to generate specific cell types like skeletal muscle fibers and cardiomyocytes affected in a certain type of MDs, hiPSCs offer a useful model for studying the disease mechanisms of MDs [96].

LGMD2I, a type of MD, is caused by fukutin-related protein (FKRP) gene mutation [97]. More than half of LGMD2I patients had cardiac involvement like progressive dilated cardiomyopathy [97-99]. Because live human cardiac cells are difficult to access and animal models failed to demonstrate cardiomyopathy, the detailed molecular or electrophysiological mechanism has not yet been defined [100]. A study conducted by El-Battrawy et al. has shed light on the pathogenesis [101]. They generated hiPSC-derived cardiomyocytes from an LGMD2I patient with dilated cardiomyopathy and found that $\mathrm{Na}^{+}, \mathrm{Ca}^{2+}$, and $\mathrm{K}^{+}$ 
channel dysfunction resulted in a reduction in amplitude and upstroke velocity of action potentials as well as decreased $\mathrm{Ca}^{2+}$ release. The former may impair the conduction of heart excitation and the rhythm, whereas the latter may reduce the contraction force of cardiomyocytes and lead to dilated cardiomyopathy. This patient-derived hiPSC cardiomyocytes model is promising in mechanistic studies of LGMD2I.

AMD, taking up over 50\% of newly certified vision impairment in England and Wales, is a leading cause of blindness [102]. AMD is a progressive disease involving multiple factors, including environment, metabolism, immunity, and genetics [103]. For AMD, there are two advanced forms, "wet" and "dry". For the former, anti-vascular endothelial growth factor agents have been widely used $[104,105]$, whereas, for the latter, there exists no effective treatment. To develop a disease-modifying therapy for dry AMD, further studies for the disease mechanisms are needed. Some evidence shows that an association exists between AMD and a dysfunctional autophagy-lysosome pathway [106-108], but the actual role autophagy plays in AMD pathophysiology remains unclear because of a lack of a satisfactory human in vitro AMD model. Edvinas et al. [109] used retinal pigment epithelium (RPE) cells generated from $\mathrm{Y} 402 \mathrm{H}$ (complement factor $\mathrm{H}(\mathrm{CFH})$ polymorphism Y402H)-AMD-patient-derived hiPSCs to set up an in vitro model and discovered that in Y402H-AMD-patient-specific RPE cells, the significantly increased C3 turnover led to autophagy dysfunction by increasing deposition of the terminal attack complex C5b-9 at the lysosomes, which resulted in lysosomal overburden and malfunction. Moreover, they found that by inhibiting C3 turnover with the compstatin analogue $\mathrm{Cp} 40$, all cellular disease phenotypes were reversed. This research shows a new link between the complement system and the autophagy-lysosome axis, contributing to revealing the disease mechanisms of AMD.

In summary, utilizing hPSC technology, we can develop disease models that previously could not be built, which helps to figure out the mechanisms of many intractable diseases.

\subsection{Models for Toxicology}

The safety test and toxicology test of a drug are an important part of the preclinical research. Drugs must be tested for safety and toxicity before they are marketed. In general, the commonly used parameters to indicate drug toxicity are the half lethal dose (LD50) or the half lethal concentration (LC50), the half effective dose (ED50), the minimum lethal dose (MLD) or minimum lethal concentration (MLC), the maximum tolerable dose (MTD) or maximum tolerable concentration (MLC), the therapeutic index (TI), the minimum effective dose (MED), the minimum toxic dose (MTD), etc. LD50 is the most important parameter of the safety test and the toxicity test. LD50 is the dose needed for a drug to cause $50 \%$ death in a group of laboratory animals, and it is obtained by experiments [110]. TI is the ratio of the LD50 to the ED50 [111]. The greater the value of TI, the smaller the ED50 and the larger the LD50 of the drug, indicating that the drug is safer. The therapeutic window is the concentration of the drug between the MED and the MTD. The drug is effective when the concentration of the drug is within the therapeutic window.

At present, there are many models used to determine the safety of drugs, including rodent models, mammalian models, small organism models, cell models, and organoid model. A common rodent model is the mouse model [112]. However, because of species differences between humans and rodent animals, the metabolic enzymes are different. The disposition of a drug between humans and animals is different [113], so the results are going to be different. Mammalian models include the pig model [114], the rabbit model [115], and so on. Mammalian models have been considered the gold standard for testing drug toxicity because mammals share the same developmental pathway as humans, and most of their organs, metabolic enzymes, and metabolic pathways are similar to humans. However, the high cost of animal models and the ethical and moral problems cannot be ignored. Small organism models include the zebrafish model [116] and the caenorhabditis elegans model [117]. Using small biological models for drug toxicity testing can obtain the reproductive, endocrine, and nervous system data of a complete individual, and the cost of small biological models is much lower than that of mammalian animal 
models, but it still cannot completely replace mammalian animal models. Common cell models include the liver cell model, the nerve cell model, the myocardial cell model, and so on. Although these models can reflect drug toxicity, they are sometimes inaccurate. For example, when using the liver cell model to evaluate drug-induced liver injury, it is not enough to use only liver parenchymal cells. The damage of liver non-parenchymal cells can also lead to liver injury. The abnormal function of Kupffer cells will lead to abnormal liver microcirculation and affect the function of liver cells. Abnormal hepatic stellate cells can lead to liver fibrosis. Through the above analysis, we can learn that each model has its own advantages and disadvantages, and researchers can choose a suitable model according to their own needs. With the development of hPSC, a low-cost, simple, convenient, and exact model has emerged. Based on cells differentiated from hPSCs, we can construct organoid models that have homology with the donor without species differences and can fully simulate the process of drug metabolism in the organ to evaluate the effects of drugs on a variety of cells, meaning we are no longer limited to one kind of cell. Organoid models can be made in a petri dish, require less starting material, and cost less. Based on these advantages, organoid models have soon become a new model for studying drug toxicity in vitro. At present, the organ-like model has been established, including brain organoids [118,119], hPSC-derived blood-brain barrier models [120], hPSC-derived cardiomyocyte organoids [121], liver organoids [122], and kidney organoids [123,124].

Sirenko et al. [125] used the hiPSC-derived model of liver cells to analyze and assess the hepatotoxicity of 240 compounds by observing the cell vitality, the nucleus shape, the average cell area and consolidation, the mitochondrial membrane potential, the accumulation of phospholipids, cytoskeleton integrity, and apoptosis, which facilitates the safety assessment of drugs and chemicals. Mun et al. [126] gradually differentiated hiPSCs into mature hepatocytes (MH) in vitro. About 22 days after differentiation, MHs began to appear as 3D spherical structures and showed a 3D morphology similar to liver parenchymal cells. When MHs embedded in Matrigel were cultured in a liver medium, liver organoids were significantly enlarged and showed the ability of liver to self-renew. It was found that the liver organoids could still maintain normal nuclear morphology after three months of culture in vitro, had glycolysis activity, and could perform the tricarboxylic acid cycle and oxidative phosphorylation. At the same time, liver organoids expressed sufficient levels of products that are expressed by mature hepatocytes, such as ALB, TTR, duct-labeled CK19, and those in the basic cytochrome CYP family (3A4, 1A2, 2A6, and 2E1). In predicting toxicological outcomes using troglitazone and acetaminophen, 3D liver organoids have advantages over two-dimensional (2D) models. Thus, the liver organoids have natural drug metabolic activity and toxicity sensitivity, which can be used for toxicity prediction, drug screening, and disease modeling.

Sirenko et al. [127] used hiPSC-derived models to evaluate the cardiotoxicity of 69 representative environmental chemicals in vitro and found that environmental pollutants altered the function of cardiomyocytes in vitro at high exposure levels, and similar chemicals had similar effects on cardiomyocytes in vitro. There have been many reports of using hiPSC-derived models to determine the cardiotoxicity of compounds or drugs [128-130]. Ni et al. [131] constructed an in vitro cardiovascular cell model using cardiomyocytes (hPSC-CMS) and endothelial cells (hPSC-ECs) induced by homologous hPSCs. The ratio of myocardial troponin T (TNNT2)-positive cardiomyocytes in this model was more than $90 \%$, and the cardiomyocytes had normal myofilament structures and electrophysiological characteristics. CD31 and CD144 double positive hiPSC-EC accounted for more than 90\%. These results demonstrate that cardiovascular cell models were established in vitro. The new safe lipid-lowering drug alirocumab, the dose-dependent cardiotoxic drug atorvastatin, and the cardiotoxic drug doxorubicin were used to verify the model, and the results were consistent with the theory. It has been proved that the safety and toxicity of lipidlowering drugs can be evaluated by this model in vitro and can promote the research and development of lipid-lowering drugs. 
With advances in cell biology, other researchers have used hiPSC-derived models to measure the nephrotoxicity [132], neurotoxicity [133], muscle toxicity [134], and other toxicities of drugs or other compounds. It is important to take into account the differences between developing and mature nerve cells, as well as the role of the blood-brain barrier, when testing drugs for neurotoxicity. The models of neurons that have been differentiated from hiPSCs include the dopaminergic neuron model [135], the cholinergic neuron model [136], the astrocyte model [137], and models of the blood-brain barrier [138]. Glutamate is an excitatory neurotransmitter, and one of its receptors is NMDAR, which was mentioned in Section 4.1. NMDAR is important for studying the effects of chemicals on neurotransmitters, but NMDAR has not been found in conventional nerve cell lines or in most stem-cell-derived neurons. Klima et al. [139] used PSC to cultivate a mixed cortical culture (MCC). Immunocytochemistry and gene expression profiles showed that MCC contained a variety of neurotransmitter receptors including NMDAR. Verified by neurotransmitter agonists and antagonists, MCC based on PSC pioneered a cellular model of the effects of chemicals on neurotransmitter receptors. Mitochondrial dysfunction can seriously affect the normal functioning of the nervous system. For ethical reasons, the current models for studying mitochondrial dysfunction are postmortem brain specimens, animal models, and 2D nervous systems [140]. However, these models do not fully mimic the complex human nervous system. Lancaster et al. [141] have developed a brain organoid model with multiple types of brain cells and 3D structures, which has become a powerful tool for modeling and evaluating mitochondrial disorders. However, this model uses hiPSCs derived from human skin fibroblasts, and the acquisition process is slow and susceptible to external environmental factors. Human skin fibroblasts are often exposed to ultraviolet radiation, which will cause DNA changes. If hiPSCs induced by the mutated fibroblasts are established using an in vitro model, the status of the patient cannot be accurately reflected. So, there are some defects in this model. Duong et al. [142] used peripheral blood mononuclear cells (PBMCs)-derived hiPSCs to construct a human brain organoid model. Because PBMCs are less affected by the environment, they mutate less than skin fibroblasts; thus, PBMCs-derived hiPSCs can more accurately reflect the patient's status. Brain organoid models derived from PBMCs have been used as in vitro model of mitochondrial disorders.

In summary, toxicity tests of hepatotoxicity, cardiotoxicity, neurotoxicity, musculotoxicity, and nephrotoxicity using hiPSC-derived models in vitro can predict the metabolism and dose range of drugs, can understand the potential toxicity of drugs, and can greatly improve the safety of drugs. It is precisely because of the numerous advantages of hiPSCderived models that they are believed to replace the existing animal models in drug safety and toxicity testing in the near future.

\subsection{Models for Precision Medicine}

Jameson et al. [143] defines precision medicine as "treatments targeted to the needs of individual patients on the basis of genetic, biomarker, phenotypic, or psychosocial characteristics that distinguish a given patient from other patients with similar clinical presentations." However, König et al. [144] believe that precision medicine is a constantly changing process, constantly collecting changes in variables and timely feedback to the in-depth study stage, assessing the patient's status, and then performing individualized treatment. To this end, what can hPSC-derived models contribute to precision medicine?

Precision medicine includes three aspects. The first one is big data analysis, which is the foundation of precision medicine and can provide multi-dimensional data. Through the collection and analysis of population data, we can analyze the real source of the disease and find the most appropriate treatment plan. The second aspect is accurate diagnosis, which can provide more detailed and accurate patient data and can help the big data system to better judge the patient's condition. Genetic testing $[145,146]$ has demonstrated its remarkable contribution to precision medicine. The third aspect is precision treatment, 
which can reduce the adverse reactions, implement more effective treatment, and even cure the difficult diseases that could not be solved in the past.

With the continuous progress of hPSC technology, hPSCs are playing an increasingly important role in precision medicine. Firstly, hPSCs can be used to construct patient-specific disease models in vitro, from which we can gain a deeper understanding of the pathogenesis of patients, and these patient-specific disease cells can be used for drug screening to achieve the most effective treatment. Tai et al. [147] have successfully reprogrammed human skin fibroblasts into hiPSCs using non-integrated Sendai virus. If the skin cell comes from a patient, the hiPSC shares the same genes as the patient and could help mimic the patient's disease [148].

Secondly, the most effective method for drug screening based on the disease model established by hPSCs is to treat according to the target. The progress of hPSC technology has made it possible to create a disease model for each patient. We can understand the progression of the disease and select the drug that is most suitable for that patient. Strikoudis et al. [149] used CRISPR/Cas9 to introduce a frameshift mutation in the HermanskyPudlak syndrome (HPS) gene and found that the edited hESC-derived lung organoids showed fibrosis changes and increased interleukin-11 (IL-11) expression. They also found that IL-11 induced fibrosis in wild-type lung organoids, whereas IL-11-deprived HPS lung organoids did not develop fibrosis. This suggests that IL-11 is a therapeutic target of idiopathic pulmonary fibrosis (IPF). Drugs that antagonize IL-11 may be used to target IPF to minimize adverse reactions and maximize therapeutic effects.

At the moment, doctors usually diagnose cancer patients clinically through pathological tissue sections, and cancer patients are treated with chemotherapy or radiation, which is very harmful to patients. It is believed that hPSC-derived models will provide important help in disease diagnosis in the future. We can take skin cells from patients and reprogram them into hiPSCs, and then differentiate them into organoids. The organoid models can not only provide us with the pathogenesis of cancer but also with therapeutic targets, according to which we can effectively treat patients, greatly saving their lives and alleviating their suffering.

Similarly, other researchers have applied hiPSCs to the precision treatment of human liver diseases [150] and central nervous system diseases [9]. hPSC-derived models play a significant role in precision medicine and run through the whole process of precision medicine. It can provide doctors with the pathogenesis of a disease, and we can use genetic testing to find possible therapeutic targets for a disease; then, through drug screening based on this target, we can find the most suitable drug for the patient. hPSC has brought great convenience to doctors and patients. This may be one of the most important treatments for genetic diseases and cancer in the future. Organoid models in hPSC-derived models may make important contributions to organ transplantation. This has also become a hot research direction recently.

\subsection{Clinical Trial in a Dish}

In the past, preclinical studies of drugs have been conducted in animals, and clinical trials have been conducted in humans. The emergence of hiPSCs has opened new avenues for preclinical research and clinical trials to investigate drug safety and toxicity at the human cellular level. This method is called clinical trial in a dish (CTID) [151]. CTID can be used to test a medical treatment for the safety or efficacy on a specific patient's cells. CTID can be used in population-specific drug development to predict not only how effective a drug will be but also how adverse reactions to the drug will be before actual clinical trials. At the same time, after CTID, researchers will choose safer drugs to enter clinical development, thus reducing drug research expenditures.

Enlarged ventricles and dysfunction are characteristic of dilated cardiomyopathy (DCM) [152]. Severe cases can result in heart failure and are kept alive by a heart transplant. Familial DCM involves more than 60 genes, the most common of which is the genetic variation that encodes the nuclear envelope proteins Lamin A/C (LMNA) [153]. LMNA mu- 
tations that cause lipodystrophy or progeria show endothelial cell (EC)-dependent vascular dysfunction leading to premature atherosclerosis [154]. In a study [155] of the mechanism by which lovastatin improves LMNA-associated dilated cardiomyopathy in vitro, Sayed et al. found that patients with LMNA-associated DCM showed clinical endothelial dysfunction and reduced function of hiPSC-derived ECs (hiPSC-ECs) derived from these patients, such as angiogenesis disorder and nitric oxide production disorder. At the same time, the restoration of hiPSC-EC function with LMNA mutation was corrected by gene editing technology. Finally, it was found that the expression of Kruppel like factor 2 of hiPSC-EC in patients with LMNA mutation was suppressed, leading to reduced cell function. Thus, the reactive hyperemia index of LMNA-related DCM patients treated with lovastatin increased, indicating that the clinical endothelial dysfunction was improved. In addition, hiPSC-EC from patients with LMNA mutations treated with lovastatin were co-cultured with hiPSC-derived cardiomyocytes (hiPSC-CM) from patients with DCM who showed improved cardiomyocyte function. At the same time, some researchers [20] used hiPSCs for CTID, combined with genomic analysis, to identify patients vulnerable to cardiotoxicity induced by specific drugs, thus enhancing drug safety in these patients and reducing the incidence of adverse reactions. In addition, biomarkers for the treatment of disease can be found when CTID is performed with hiPSCs. Han et al. [156] found that the levels of circular RNA E3 ubiquitin-protein ligase (CircITCH) in both hiPSC-derived cardiomyocytes and patients who suffered from doxorubicin-induced cardiomyopathy decreased. However, cardiotoxicity was successfully prevented in mice induced by doxorubicin-induced toxicity after $\mathrm{CircITCH}$ overexpression using an adeno-associated virus serotype 9 vector. These results indicate that $\mathrm{CircITCH}$ is an important biomarker of doxorubicin-induced cardiomyopathy, and, based on this, drugs targeting doxorubicin-induced cardiomyopathy can be designed. In addition, the use of patient-specific hiPSCs for CTID can also identify at-risk populations, simulate clinical trials of toxic drugs [157], and identify the toxicity of drugs [158].

There have been several studies exploring the usefulness of hiPSC-derived cardiomyocytes in predicting drug-induced cardiotoxicity. The results vary. Stillitano, et al. [159] selected extreme patients who were either supersensitive or insensitive to drug-induced long QT and generated subject-specific hiPSC-derived cardiomyocytes. The authors found a good correlation between the response of patients with the response of their corresponding invitro-cultured hiPSC-derived cardiomyocytes to a cardiotoxic drug sotalol. In another study, Shinozawa, et al. [160] took a similar approach and found a positive correlation between the clinical QT intervals and the field potential duration prolongation values generated from cell assays at relevant concentrations of a QT-prolonging drug moxifloxacin. In contrast, a more recent study by Blinova et al. [161] failed to find a correlation between in vivo and in vitro data. The authors discussed that the possible reasons could be immaturity of hiPSC-derived cardiomyocytes, variation in stem cell differentiation, loss of epigenetic signatures, variation in cohort, and variation in the tested drug concentration range. Therefore, improving maturation and standardizing differentiation protocols are urgently needed.

To sum up, hiPSCs have been used by many researchers to carry out CTID, and some achievements have been made. Compared with traditional preclinical and clinical studies, CTID can save money and time and prevent serious adverse reactions. Although hiPSCs have not been used for a long time in CTID, we believe that hiPSCs have potential in drug discovery, prediction of adverse reactions, diagnosis, and treatment of diseases in the future once technical problems have been overcome.

\subsection{Post-Clinical Studies}

Post-clinical study is the stage of applied research after a new drug is marketed. Its purpose is to study the efficacy and adverse reactions of the drug in the case of widespread use, to evaluate the benefits and risks of the drug when used in general or special populations, and to improve its dosage. Here, we propose that, by establishing hiPSCs from patients who have used the drug of interest, we will be able to correlate the data of clinical drug use with hiPSC-derived in vitro models and then dissect the mechanisms of drug 
effect and toxicology. The results will be useful information to guide the rational use of drugs and the re-evaluation of drug safety.

\section{Perspective}

Owing to the capability of unlimited self-renewal and differentiating into any human somatic cells, hPSCs have great potential to build in vitro models for drug discovery and development. hPSC-derived in vitro models, either directly from patients or modified by genome editing technology, can improve the cost-effectiveness and the success rate of drug discovery and development. These models play an active role in phenotypic screening, target-based screening, network-based screening, and post-clinical studies for disease mechanism, drug development, rational drug use, and drug safety re-evaluation.

In vitro models for drug testing should be robust, reproducible, scalable, and costeffective. Scale-up culture or progenitor cell expansion enable the production of large numbers of cells of interest. For hPSC-derived hepatocytes, researchers have developed different ways to increase the yield [126,162-166]. Reproducibility remains as an issue to be addressed. Poor reproducibility is due to unstandardized differentiation protocols and incomplete cell characterization. A recent review by Volpato and Webber nicely summarized the reasons and possible solutions to this issue [167]. The differentiation of hPSCs is a complex and time-consuming process, requiring different growth factors and extracellular matrix components, which dramatically increase the cost of the experiments. One of the strategies to make it more cost-effective and to allow pharma industries to adopt this model is the use of small molecules to replace growth factors. Immaturity of hPSC-derived cells is another problem that researchers currently tackle. Ethical issues related particularly to brain organoids has drawn attention in this field. Developing mature brain organoids for drug discovery and development may face a dilemma. On the one hand, we need mature brain organoids to model diseases and to test drug candidates. On the other hand, mature brain organoids with consciousness or cognition should not be developed and used in drug testing. This issue is waiting for updated regulation from stem cell societies and authorities [168]. Hopefully with the progress of related techniques, such as organoid technology, genome editing, and direct differentiation, hPSC-derived models will bring more benefits to the health of human beings.

Author Contributions: Conceptualization, Y.-R.L.; writing-original draft preparation, X.L., J.T. and Y.-R.L.; writing-review \& editing, X.L., J.T. and Y.-R.L.; visualization, X.L. and J.T.; supervision, Y.-R.L.; project administration, Y.-R.L.; funding acquisition, Y.-R.L. All authors have read and agreed to the published version of the manuscript.

Funding: This research received no external funding.

Institutional Review Board Statement: Not applicable.

Informed Consent Statement: Not applicable.

Data Availability Statement: Not applicable.

Acknowledgments: We would like to thank the research funding from Fudan University.

Conflicts of Interest: The authors declare no conflict of interest.

\section{References}

1. Lei, Y.; Schaffer, D.V. A fully defined and scalable 3D culture system for human pluripotent stem cell expansion and differentiation. Proc. Natl. Acad. Sci. USA 2013, 110, E5039-E5048. [CrossRef] [PubMed]

2. Cai, Y.; Dai, X.; Zhang, Q.; Dai, Z. Gene expression of OCT4, SOX2, KLF4 and MYC (OSKM) induced pluripotent stem cells: Identification for potential mechanisms. Diagn. Pathol. 2015, 10, 35. [CrossRef] [PubMed]

3. Doss, M.X.; Sachinidis, A. Current Challenges of iPSC-Based Disease Modeling and Therapeutic Implications. Cells 2019, 8, 403. [CrossRef] [PubMed]

4. Menasché, P.; Vanneaux, V.; Hagège, A.; Bel, A.; Cholley, B.; Parouchev, A.; Cacciapuoti, I.; Al-Daccak, R.; Benhamouda, N.; Blons, H.; et al. Transplantation of Human Embryonic Stem Cell-Derived Cardiovascular Progenitors for Severe Ischemic Left Ventricular Dysfunction. J. Am. Coll. Cardiol. 2018, 71, 429-438. [CrossRef] 
5. Cyranoski, D. How human embryonic stem cells sparked a revolution. Nature 2018, 555, 428-430. [CrossRef]

6. Augustyniak, J.; Bertero, A.; Coccini, T.; Baderna, D.; Buzanska, L.; Caloni, F. Organoids are promising tools for species-specific in vitro toxicological studies. J. Appl. Toxicol. 2019, 39, 1610-1622. [CrossRef]

7. Lou, Y.R.; Leung, A.W. Next generation organoids for biomedical research and applications. Biotechnol. Adv. 2018, 36, 132-149. [CrossRef]

8. Rowe, R.G.; Daley, G.Q. Induced pluripotent stem cells in disease modelling and drug discovery. Nat. Rev. Genet. 2019, 20, 377-388. [CrossRef]

9. Silva, M.C.; Haggarty, S.J. Human pluripotent stem cell-derived models and drug screening in CNS precision medicine. Ann. N. Y. Acad. Sci. 2020, 1471, 18-56. [CrossRef]

10. Garcia-Leon, J.A.; Caceres-Palomo, L.; Sanchez-Mejias, E.; Mejias-Ortega, M.; Nuñez-Diaz, C.; Fernandez-Valenzuela, J.J.; SanchezVaro, R.; Davila, J.C.; Vitorica, J.; Gutierrez, A. Human Pluripotent Stem Cell-Derived Neural Cells as a Relevant Platform for Drug Screening in Alzheimer's Disease. Int. J. Mol. Sci. 2020, 21, 6867. [CrossRef]

11. Han, C.; Chaineau, M.; Chen, C.X.Q.; Beitel, L.K.; Durcan, T.M. Open Science Meets Stem Cells: A New Drug Discovery Approach for Neurodegenerative Disorders. Front. Neurosci. 2018, 12, 47. [CrossRef]

12. Dahlin, J.L.; Inglese, J.; Walters, M.A. Mitigating risk in academic preclinical drug discovery. Nat. Rev. Drug Discov. 2015, 14, 279-294. [CrossRef]

13. Lal, S.; Li, A.; Dos Remedios, C. Limitations in Translating Animal Studies to Humans in Cardiovascular Disease. J. Cardiovasc. Transl. Res. 2016, 9, 165-166. [CrossRef]

14. Paik, D.T.; Chandy, M.; Wu, J.C. Patient and Disease-Specific Induced Pluripotent Stem Cells for Discovery of Personalized Cardiovascular Drugs and Therapeutics. Pharmacol. Rev. 2020, 72, 320-342. [CrossRef]

15. DiMasi, J.A.; Hansen, R.W.; Grabowski, H.G. The price of innovation: New estimates of drug development costs. J. Health Econ. 2003, 22, 151-185. [CrossRef]

16. DiMasi, J.A.; Feldman, L.; Seckler, A.; Wilson, A. Trends in risks associated with new drug development: Success rates for investigational drugs. Clin. Pharmacol. Ther. 2010, 87, 272-277. [CrossRef]

17. Craveiro, N.S.; Lopes, B.S.; Tomás, L.; Almeida, S.F. Drug Withdrawal Due to Safety: A Review of the Data Supporting Withdrawal Decision. Curr. Drug Saf. 2020, 15, 4-12. [CrossRef]

18. Onakpoya, I.J.; Heneghan, C.J.; Aronson, J.K. Post-marketing withdrawal of 462 medicinal products because of adverse drug reactions: A systematic review of the world literature. BMC Med. 2016, 14, 10. [CrossRef]

19. McNeish, J.; Gardner, J.P.; Wainger, B.J.; Woolf, C.J.; Eggan, K. From Dish to Bedside: Lessons Learned While Translating Findings from a Stem Cell Model of Disease to a Clinical Trial. Cell Stem Cell 2015, 17, 8-10. [CrossRef]

20. Lam, C.K.; Wu, J.C. Clinical Trial in a Dish: Using Patient-Derived Induced Pluripotent Stem Cells to Identify Risks of DrugInduced Cardiotoxicity. Arterioscler. Thromb. Vasc. Biol. 2021, 41, 1019-1031. [CrossRef]

21. Pravenec, M.; Křen, V.; Landa, V.; Mlejnek, P.; Musilová, A.; Šilhavý, J.; Šimáková, M.; Zídek, V. Recent progress in the genetics of spontaneously hypertensive rats. Physiol. Res. 2014, 63, S1-S8. [CrossRef]

22. Curia, G.; Longo, D.; Biagini, G.; Jones, R.S.; Avoli, M. The pilocarpine model of temporal lobe epilepsy. J. Neurosci. Methods 2008, 172, 143-157. [CrossRef]

23. Herault, Y.; Delabar, J.M.; Fisher, E.M.C.; Tybulewicz, V.L.J.; Yu, E.; Brault, V. Rodent models in Down syndrome research: Impact and future opportunities. Dis. Models Mech. 2017, 10, 1165-1186. [CrossRef]

24. Li, F.; Wang, Z.; Hu, F.; Su, L. Cell Culture Models and Animal Models for HBV Study. Adv. Exp. Med. Biol. 2020, 1179, 109-135. [CrossRef]

25. Chin, R.M.; Panavas, T.; Brown, J.M.; Johnson, K.K. Patient-derived lymphoblastoid cell lines harboring mitochondrial DNA mutations as tool for small molecule drug discovery. BMC Res. Notes 2018, 11, 205. [CrossRef]

26. Xicoy, H.; Wieringa, B.; Martens, G.J. The SH-SY5Y cell line in Parkinson's disease research: A systematic review. Mol. Neurodegener. 2017, 12, 10. [CrossRef]

27. Zeilinger, K.; Freyer, N.; Damm, G.; Seehofer, D.; Knöspel, F. Cell sources for in vitro human liver cell culture models. Exp. Biol. Med. 2016, 241, 1684-1698. [CrossRef]

28. Gao, X.; Liu, Y. A transcriptomic study suggesting human iPSC-derived hepatocytes potentially offer a better in vitro model of hepatotoxicity than most hepatoma cell lines. Cell Biol. Toxicol. 2017, 33, 407-421. [CrossRef]

29. Karakikes, I.; Ameen, M.; Termglinchan, V.; Wu, J.C. Human induced pluripotent stem cell-derived cardiomyocytes: Insights into molecular, cellular, and functional phenotypes. Circ. Res. 2015, 117, 80-88. [CrossRef]

30. Kaul, A.; Gordon, C.; Crow, M.K.; Touma, Z.; Urowitz, M.B.; van Vollenhoven, R.; Ruiz-Irastorza, G.; Hughes, G. Systemic lupus erythematosus. Nat. Rev. Dis. Primers 2016, 2, 16039. [CrossRef]

31. Chen, L.; Morris, D.L.; Vyse, T.J. Genetic advances in systemic lupus erythematosus: An update. Curr. Opin. Rheumatol. 2017, 29, 423-433. [CrossRef] [PubMed]

32. Tsokos, G.C.; Lo, M.S.; Costa Reis, P.; Sullivan, K.E. New insights into the immunopathogenesis of systemic lupus erythematosus. Nat. Rev. Rheumatol. 2016, 12, 716-730. [CrossRef] [PubMed] 
33. Zucchi, D.; Elefante, E.; Calabresi, E.; Signorini, V.; Bortoluzzi, A.; Tani, C. One year in review 2019: Systemic lupus erythematosus. Clin. Exp. Rheumatol. 2019, 37, 715-722. [PubMed]

34. Zhu, T.Y.; Tam, L.S.; Li, E.K. Cost-of-illness studies in systemic lupus erythematosus: A systematic review. Arthritis Care Res. 2011, 63, 751-760. [CrossRef]

35. Rivas-Larrauri, F.; Yamazaki-Nakashimada, M.A. Systemic lupus erythematosus: Is it one disease? Reumatol. Clin. 2016, 12, 274-281. [CrossRef]

36. Dörner, T.; Furie, R. Novel paradigms in systemic lupus erythematosus. Lancet 2019, 393, 2344-2358. [CrossRef]

37. Li, W.; Liu, D.; Zheng, F.; Zeng, Z.; Cai, W.; Luan, S.; Hong, X.; Tang, D.; Yin, L.H.; Dai, Y. Generation of Systemic Lupus Erythematosus Patient-Derived Induced Pluripotent Stem Cells from Blood. Stem Cells Dev. 2021, 30, 227-233. [CrossRef]

38. Fick, G.M.; Gabow, P.A. Natural history of autosomal dominant polycystic kidney disease. Annu. Rev. Med. 1994, 45, 23-29. [CrossRef]

39. Benedetti, V.; Brizi, V.; Guida, P.; Tomasoni, S.; Ciampi, O.; Angeli, E.; Valbusa, U.; Benigni, A.; Remuzzi, G.; Xinaris, C. Engineered Kidney Tubules for Modeling Patient-Specific Diseases and Drug Discovery. EBioMedicine 2018, 33, 253-268. [CrossRef]

40. Mo, J.; Anastasaki, C.; Chen, Z.; Shipman, T.; Papke, J.; Yin, K.; Gutmann, D.H.; Le, L.Q. Humanized neurofibroma model from induced pluripotent stem cells delineates tumor pathogenesis and developmental origins. J. Clin. Investg. 2021, 131, e139807. [CrossRef]

41. Boch, J.; Scholze, H.; Schornack, S.; Landgraf, A.; Hahn, S.; Kay, S.; Lahaye, T.; Nickstadt, A.; Bonas, U. Breaking the code of DNA binding specificity of TAL-type III effectors. Science 2009, 326, 1509-1512. [CrossRef]

42. Bogdanove, A.J.; Voytas, D.F. TAL effectors: Customizable proteins for DNA targeting. Science 2011, 333, 1843-1846. [CrossRef]

43. Porteus, M.H.; Carroll, D. Gene targeting using zinc finger nucleases. Nat. Biotechnol. 2005, 23, 967-973. [CrossRef]

44. Doudna, J.A.; Charpentier, E. Genome editing. The new frontier of genome engineering with CRISPR-Cas9. Science 2014, 346, 1258096. [CrossRef]

45. Jinek, M.; Chylinski, K.; Fonfara, I.; Hauer, M.; Doudna, J.A.; Charpentier, E. A programmable dual-RNA-guided DNA endonuclease in adaptive bacterial immunity. Science 2012, 337, 816-821. [CrossRef]

46. Mali, P.; Yang, L.; Esvelt, K.M.; Aach, J.; Guell, M.; DiCarlo, J.E.; Norville, J.E.; Church, G.M. RNA-guided human genome engineering via Cas9. Science 2013, 339, 823-826. [CrossRef]

47. Leung, A.W.; Broton, C.; Bogacheva, M.S.; Xiao, A.Z.; Garcia-Castro, M.I.; Lou, Y.R. RNA-based CRISPR-Mediated Loss-ofFunction Mutagenesis in Human Pluripotent Stem Cells. J. Mol. Biol. 2020, 432, 3956-3964. [CrossRef]

48. Christidi, E.; Huang, H.M.; Brunham, L.R. CRISPR/Cas9-mediated genome editing in human stem cell-derived cardiomyocytes: Applications for cardiovascular disease modelling and cardiotoxicity screening. Drug Discov. Today Technol. 2018, 28, 13-21. [CrossRef]

49. Suh, W. A new era of disease modeling and drug discovery using induced pluripotent stem cells. Arch. Pharm. Res. 2017, 40, 1-12. [CrossRef]

50. Artero Castro, A.; Lukovic, D.; Jendelova, P.; Erceg, S. Concise Review: Human Induced Pluripotent Stem Cell Models of Retinitis Pigmentosa. Stem Cells 2018, 36, 474-481. [CrossRef]

51. Lane, A.; Jovanovic, K.; Shortall, C.; Ottaviani, D.; Panes, A.B.; Schwarz, N.; Guarascio, R.; Hayes, M.J.; Palfi, A.; Chadderton, N.; et al. Modeling and Rescue of RP2 Retinitis Pigmentosa Using iPSC-Derived Retinal Organoids. Stem Cell Rep. 2020, 15, 67-79. [CrossRef]

52. Le Verche, V.; Przedborski, S. Is amyotrophic lateral sclerosis a mitochondrial channelopathy? Neuron 2010, 67, 523-524. [CrossRef]

53. Petrov, D.; Daura, X.; Zagrovic, B. Effect of Oxidative Damage on the Stability and Dimerization of Superoxide Dismutase 1. Biophys. J. 2016, 110, 1499-1509. [CrossRef]

54. Kim, B.W.; Ryu, J.; Jeong, Y.E.; Kim, J.; Martin, L.J. Human Motor Neurons With SOD1-G93A Mutation Generated From CRISPR/Cas9 Gene-Edited iPSCs Develop Pathological Features of Amyotrophic Lateral Sclerosis. Front. Cell Neurosci. 2020, 14, 604171. [CrossRef]

55. Zhang, T.; Moss, A.; Cong, P.; Pan, M.; Chang, B.; Zheng, L.; Fang, Q.; Zareba, W.; Robinson, J.; Lin, C.; et al. LQTS gene LOVD database. Hum. Mutat. 2010, 31, E1801-E1810. [CrossRef]

56. Wang, Y.; Liang, P.; Lan, F.; Wu, H.; Lisowski, L.; Gu, M.; Hu, S.; Kay, M.A.; Urnov, F.D.; Shinnawi, R.; et al. Genome editing of isogenic human induced pluripotent stem cells recapitulates long QT phenotype for drug testing. J. Am. Coll. Cardiol. 2014, 64, 451-459. [CrossRef]

57. Reith, W. Neurodegenerative diseases. Radiologe 2018, 58, 241-258. [CrossRef]

58. Dawson, T.M.; Golde, T.E.; Lagier-Tourenne, C. Animal models of neurodegenerative diseases. Nat. Neurosci. 2018, 21, 1370-1379. [CrossRef]

59. Dugger, B.N.; Dickson, D.W. Pathology of Neurodegenerative Diseases. Cold Spring Harb. Perspect. Biol. 2017, 9, a028035. [CrossRef]

60. Singh, A.; Kukreti, R.; Saso, L.; Kukreti, S. Oxidative Stress: A Key Modulator in Neurodegenerative Diseases. Molecules 2019, 24, 1583. [CrossRef]

61. Millecamps, S.; Julien, J.P. Axonal transport deficits and neurodegenerative diseases. Nat. Rev. Neurosci. 2013, 14, 161-176. [CrossRef] [PubMed] 
62. Stephenson, J.; Nutma, E.; van der Valk, P.; Amor, S. Inflammation in CNS neurodegenerative diseases. Immunology 2018, 154, 204-219. [CrossRef] [PubMed]

63. Garcia-Leon, J.A.; Vitorica, J.; Gutierrez, A. Use of human pluripotent stem cell-derived cells for neurodegenerative disease modeling and drug screening platform. Future Med. Chem. 2019, 11, 1305-1322. [CrossRef] [PubMed]

64. Polanco, J.C.; Li, C.; Bodea, L.G.; Martinez-Marmol, R.; Meunier, F.A.; Götz, J. Amyloid- $\beta$ and tau complexity-Towards improved biomarkers and targeted therapies. Nat. Rev. Neurol. 2018, 14, 22-39. [CrossRef]

65. García-León, J.A.; Cabrera-Socorro, A.; Eggermont, K.; Swijsen, A.; Terryn, J.; Fazal, R.; Nami, F.; Ordovás, L.; Quiles, A.; Lluis, F.; et al. Generation of a human induced pluripotent stem cell-based model for tauopathies combining three microtubule-associated protein TAU mutations which displays several phenotypes linked to neurodegeneration. Alzheimer Dement. 2018, 14, 1261-1280. [CrossRef]

66. Hallett, P.J.; Deleidi, M.; Astradsson, A.; Smith, G.A.; Cooper, O.; Osborn, T.M.; Sundberg, M.; Moore, M.A.; Perez-Torres, E.; Brownell, A.L.; et al. Successful function of autologous iPSC-derived dopamine neurons following transplantation in a non-human primate model of Parkinson's disease. Cell Stem Cell 2015, 16, 269-274. [CrossRef]

67. Barker, R.A.; Parmar, M.; Kirkeby, A.; Björklund, A.; Thompson, L.; Brundin, P. Are Stem Cell-Based Therapies for Parkinson's Disease Ready for the Clinic in 2016? J. Parkinson Dis. 2016, 6, 57-63. [CrossRef]

68. Sridhar, A.; Hoshino, A.; Finkbeiner, C.R.; Chitsazan, A.; Dai, L.; Haugan, A.K.; Eschenbacher, K.M.; Jackson, D.L.; Trapnell, C.; Bermingham-McDonogh, O.; et al. Single-Cell Transcriptomic Comparison of Human Fetal Retina, hPSC-Derived Retinal Organoids, and Long-Term Retinal Cultures. Cell Rep. 2020, 30, 1644-1659. [CrossRef]

69. Griesi-Oliveira, K.; Fogo, M.S.; Pinto, B.G.G.; Alves, A.Y.; Suzuki, A.M.; Morales, A.G.; Ezquina, S.; Sosa, O.J.; Sutton, G.J.; Sunaga-Franze, D.Y.; et al. Transcriptome of iPSC-derived neuronal cells reveals a module of co-expressed genes consistently associated with autism spectrum disorder. Mol. Psychiatry 2021, 26, 1589-1605. [CrossRef]

70. Koivumäki, J.T.; Naumenko, N.; Tuomainen, T.; Takalo, J.; Oksanen, M.; Puttonen, K.A.; Lehtonen, Š.; Kuusisto, J.; Laakso, M.; Koistinaho, J.; et al. Structural Immaturity of Human iPSC-Derived Cardiomyocytes: In Silico Investigation of Effects on Function and Disease Modeling. Front. Physiol. 2018, 9, 80. [CrossRef]

71. Burke, E.E.; Chenoweth, J.G.; Shin, J.H.; Collado-Torres, L.; Kim, S.-K.; Micali, N.; Wang, Y.; Colantuoni, C.; Straub, R.E.; Hoeppner, D.J.; et al. Dissecting transcriptomic signatures of neuronal differentiation and maturation using iPSCs. Nat. Commun. 2020, 11, 462. [CrossRef]

72. Kolanowski, T.J.; Busek, M.; Schubert, M.; Dmitrieva, A.; Binnewerg, B.; Pöche, J.; Fisher, K.; Schmieder, F.; Grünzner, S.; Hansen, S.; et al. Enhanced structural maturation of human induced pluripotent stem cell-derived cardiomyocytes under a controlled microenvironment in a microfluidic system. Acta Biomater. 2020, 102, 273-286. [CrossRef]

73. Amaratunga, D.; Göhlmann, H.; Peeters, P.J. 3.05-Microarrays. In Comprehensive Medicinal Chemistry II; Taylor, J.B., Triggle, D.J., Eds.; Elsevier: Oxford, UK, 2007; pp. 87-106. [CrossRef]

74. Kobayashi, H.; Hatakeyama, H.; Nishimura, H.; Yokota, M.; Suzuki, S.; Tomabechi, Y.; Shirouzu, M.; Osada, H.; Mimaki, M.; Goto, Y.I.; et al. Chemical reversal of abnormalities in cells carrying mitochondrial DNA mutations. Nat. Chem. Biol. 2021, 17, 335-343. [CrossRef]

75. Zhang, W.B.; Ross, P.J.; Tu, Y.; Wang, Y.; Beggs, S.; Sengar, A.S.; Ellis, J.; Salter, M.W. Fyn Kinase regulates GluN2B subunitdominant NMDA receptors in human induced pluripotent stem cell-derived neurons. Sci. Rep. 2016, 6, 23837. [CrossRef]

76. Warchal, S.J.; Unciti-Broceta, A.; Carragher, N.O. Next-generation phenotypic screening. Future Med. Chem. 2016, 8, 1331-1347. [CrossRef]

77. Li, Z.; Cvijic, M.E.; Zhang, L. 2.15-Cellular Imaging in Drug Discovery: Imaging and Informatics for Complex Cell Biology. In Comprehensive Medicinal Chemistry III; Chackalamannil, S., Rotella, D., Ward, S.E., Eds.; Elsevier: Oxford, UK, 2017 ; pp. 362-387. [CrossRef]

78. Eggert, U.S. The why and how of phenotypic small-molecule screens. Nat. Chem. Biol. 2013, 9, 206-209. [CrossRef]

79. Swinney, D.C.; Anthony, J. How were new medicines discovered? Nat. Rev. Drug Discov. 2011, 10, 507-519. [CrossRef]

80. World Health Organization. Global Tuberculosis Report 2018; World Health Organization: Geneva, Switzerland, 2018.

81. Cole, S.T.; Brosch, R.; Parkhill, J.; Garnier, T.; Churcher, C.; Harris, D.; Gordon, S.V.; Eiglmeier, K.; Gas, S.; Barry, C.E., III; et al. Deciphering the biology of Mycobacterium tuberculosis from the complete genome sequence. Nature 1998, 393, 537-544. [CrossRef]

82. Koul, A.; Arnoult, E.; Lounis, N.; Guillemont, J.; Andries, K. The challenge of new drug discovery for tuberculosis. Nature 2011, 469, 483-490. [CrossRef]

83. Han, H.W.; Seo, H.H.; Jo, H.Y.; Han, H.J.; Falcão, V.C.A.; Delorme, V.; Heo, J.; Shum, D.; Choi, J.H.; Lee, J.M.; et al. Drug Discovery Platform Targeting M. tuberculosis with Human Embryonic Stem Cell-Derived Macrophages. Stem Cell Rep. 2019, 13, 980-991. [CrossRef]

84. Imamura, K.; Izumi, Y.; Watanabe, A.; Tsukita, K.; Woltjen, K.; Yamamoto, T.; Hotta, A.; Kondo, T.; Kitaoka, S.; Ohta, A.; et al. The $\mathrm{Src} / \mathrm{c}-\mathrm{Abl}$ pathway is a potential therapeutic target in amyotrophic lateral sclerosis. Sci. Transl. Med. 2017, 9, eaaf3962. [CrossRef]

85. Hopkins, A.L. Network pharmacology. Nat. Biotechnol. 2007, 25, 1110-1111. [CrossRef] 
86. Barabási, A.L.; Gulbahce, N.; Loscalzo, J. Network medicine: A network-based approach to human disease. Nat. Rev. Genet. 2011, 12, 56-68. [CrossRef]

87. Nichols, E.; Szoeke, C.E.; Vollset, S.E.; Abbasi, N.; Abd-Allah, F.; Abdela, J.; Aichour, M.T.E.; Akinyemi, R.O.; Alahdab, F.; Asgedom, S.W.; et al. Global, regional, and national burden of Alzheimer's disease and other dementias, 1990-2016: A systematic analysis for the Global Burden of Disease Study 2016. Lancet Neurol. 2019, 18, 88-106. [CrossRef]

88. Querfurth, H.W.; LaFerla, F.M. Alzheimer's disease. N. Engl. J. Med. 2010, 362, 329-344. [CrossRef]

89. Karch, C.M.; Goate, A.M. Alzheimer's disease risk genes and mechanisms of disease pathogenesis. Biol. Psychiatry 2015, 77, 43-51. [CrossRef]

90. Kunkle, B.W.; Grenier-Boley, B.; Sims, R.; Bis, J.C.; Damotte, V.; Naj, A.C.; Boland, A.; Vronskaya, M.; van der Lee, S.J.; Amlie-Wolf, A.; et al. Genetic meta-analysis of diagnosed Alzheimer's disease identifies new risk loci and implicates $A \beta$, tau, immunity and lipid processing. Nat. Genet. 2019, 51, 414-430. [CrossRef]

91. James, B.D.; Bennett, D.A. Causes and Patterns of Dementia: An Update in the Era of Redefining Alzheimer's Disease. Annu. Rev. Public Health 2019, 40, 65-84. [CrossRef]

92. Hampel, H.; Vergallo, A.; Aguilar, L.F.; Benda, N.; Broich, K.; Cuello, A.C.; Cummings, J.; Dubois, B.; Federoff, H.J.; Fiandaca, M.; et al. Precision pharmacology for Alzheimer's disease. Pharmacol. Res. 2018, 130, 331-365. [CrossRef]

93. Park, J.C.; Jang, S.Y.; Lee, D.; Lee, J.; Kang, U.; Chang, H.; Kim, H.J.; Han, S.H.; Seo, J.; Choi, M.; et al. A logical network-based drug-screening platform for Alzheimer's disease representing pathological features of human brain organoids. Nat. Commun. 2021, 12, 280. [CrossRef]

94. Theodoris, C.V.; Zhou, P.; Liu, L.; Zhang, Y.; Nishino, T.; Huang, Y.; Kostina, A.; Ranade, S.S.; Gifford, C.A.; Uspenskiy, V.; et al. Network-based screen in iPSC-derived cells reveals therapeutic candidate for heart valve disease. Science 2021, 371. [CrossRef] [PubMed]

95. Garg, V.; Muth, A.N.; Ransom, J.F.; Schluterman, M.K.; Barnes, R.; King, I.N.; Grossfeld, P.D.; Srivastava, D. Mutations in NOTCH1 cause aortic valve disease. Nature 2005, 437, 270-274. [CrossRef] [PubMed]

96. Xia, G.; Terada, N.; Ashizawa, T. Human iPSC Models to Study Orphan Diseases: Muscular Dystrophies. Curr. Stem Cell Rep. 2018, 4, 299-309. [CrossRef] [PubMed]

97. Walter, M.C.; Petersen, J.A.; Stucka, R.; Fischer, D.; Schröder, R.; Vorgerd, M.; Schroers, A.; Schreiber, H.; Hanemann, C.O.; Knirsch, U.; et al. FKRP (826C>A) frequently causes limb-girdle muscular dystrophy in German patients. J. Med. Genet. 2004, 41, e50. [CrossRef]

98. Poppe, M.; Cree, L.; Bourke, J.; Eagle, M.; Anderson, L.V.; Birchall, D.; Brockington, M.; Buddles, M.; Busby, M.; Muntoni, F.; et al. The phenotype of limb-girdle muscular dystrophy type 2I. Neurology 2003, 60, 1246-1251. [CrossRef]

99. Poppe, M.; Bourke, J.; Eagle, M.; Frosk, P.; Wrogemann, K.; Greenberg, C.; Muntoni, F.; Voit, T.; Straub, V.; Hilton-Jones, D.; et al. Cardiac and respiratory failure in limb-girdle muscular dystrophy 2I. Ann. Neurol. 2004, 56, 738-741. [CrossRef]

100. Krag, T.O.; Vissing, J. A New Mouse Model of Limb-Girdle Muscular Dystrophy Type 2I Homozygous for the Common L276I Mutation Mimicking the Mild Phenotype in Humans. J. Neuropathol. Exp. Neurol. 2015, 74, 1137-1146. [CrossRef]

101. El-Battrawy, I.; Zhao, Z.; Lan, H.; Li, X.; Yücel, G.; Lang, S.; Sattler, K.; Schünemann, J.D.; Zimmermann, W.H.; Cyganek, L.; et al. Ion Channel Dysfunctions in Dilated Cardiomyopathy in Limb-Girdle Muscular Dystrophy. Circ. Genom. Precis. Med. 2018, 11, e001893. [CrossRef]

102. Bunce, C.; Xing, W.; Wormald, R. Causes of blind and partial sight certifications in England and Wales: April 2007-March 2008. Eye 2010, 24, 1692-1699. [CrossRef]

103. Nowak, J.Z. Age-related macular degeneration (AMD): Pathogenesis and therapy. Pharmacol. Rep. 2006, 58, 353-363.

104. Gonzales, C.R. Enhanced efficacy associated with early treatment of neovascular age-related macular degeneration with pegaptanib sodium: An exploratory analysis. Retina 2005, 25, 815-827. [CrossRef]

105. Colquitt, J.L.; Jones, J.; Tan, S.C.; Takeda, A.; Clegg, A.J.; Price, A. Ranibizumab and pegaptanib for the treatment of age-related macular degeneration: A systematic review and economic evaluation. Health Technol. Assess. 2008, 12, 1-222. [CrossRef]

106. Wang, A.L.; Lukas, T.J.; Yuan, M.; Du, N.; Tso, M.O.; Neufeld, A.H. Autophagy and exosomes in the aged retinal pigment epithelium: Possible relevance to drusen formation and age-related macular degeneration. PLoS ONE 2009, 4, e4160. [CrossRef]

107. Mitter, S.K.; Song, C.; Qi, X.; Mao, H.; Rao, H.; Akin, D.; Lewin, A.; Grant, M.; Dunn, W., Jr.; Ding, J.; et al. Dysregulated autophagy in the RPE is associated with increased susceptibility to oxidative stress and AMD. Autophagy 2014, 10, 1989-2005. [CrossRef]

108. El-Asrag, M.E.; Sergouniotis, P.I.; McKibbin, M.; Plagnol, V.; Sheridan, E.; Waseem, N.; Abdelhamed, Z.; McKeefry, D.; Van Schil, K.; Poulter, J.A.; et al. Biallelic mutations in the autophagy regulator DRAM2 cause retinal dystrophy with early macular involvement. Am. J. Hum. Genet. 2015, 96, 948-954. [CrossRef]

109. Cerniauskas, E.; Kurzawa-Akanbi, M.; Xie, L.; Hallam, D.; Moya-Molina, M.; White, K.; Steel, D.; Doherty, M.; Whitfield, P.; Al-Aama, J.; et al. Complement modulation reverses pathology in $\mathrm{Y} 402 \mathrm{H}$-retinal pigment epithelium cell model of age-related macular degeneration by restoring lysosomal function. Stem Cells Transl. Med. 2020, 9, 1585-1603. [CrossRef]

110. Paget, E. The LD50 test. Acta Pharmacol. Toxicol. 1983, 52 (Suppl. S2), 6-19. [CrossRef]

111. Muller, P.Y.; Milton, M.N. The determination and interpretation of the therapeutic index in drug development. Nat. Rev. Drug Discov. 2012, 11, 751-761. [CrossRef] 
112. Rusyn, I.; Gatti, D.M.; Wiltshire, T.; Kleeberger, S.R.; Threadgill, D.W. Toxicogenetics: Population-based testing of drug and chemical safety in mouse models. Pharmacogenomics 2010, 11, 1127-1136. [CrossRef]

113. Clark, M.; Steger-Hartmann, T. A big data approach to the concordance of the toxicity of pharmaceuticals in animals and humans. Regul. Toxicol. Pharmacol. 2018, 96, 94-105. [CrossRef]

114. Stricker-Krongrad, A.; Shoemake, C.R.; Pereira, M.E.; Gad, S.C.; Brocksmith, D.; Bouchard, G.F. Miniature Swine Breeds in Toxicology and Drug Safety Assessments: What to Expect during Clinical and Pathology Evaluations. Toxicol. Pathol. 2016, 44, 421-427. [CrossRef]

115. Foote, R.H.; Carney, E.W. The rabbit as a model for reproductive and developmental toxicity studies. Reprod. Toxicol. 2000, 14, 477-493. [CrossRef]

116. Cassar, S.; Adatto, I.; Freeman, J.L.; Gamse, J.T.; Iturria, I.; Lawrence, C.; Muriana, A.; Peterson, R.T.; Van Cruchten, S.; Zon, L.I. Use of Zebrafish in Drug Discovery Toxicology. Chem. Res. Toxicol. 2020, 33, 95-118. [CrossRef]

117. Hunt, P.R. The C. elegans model in toxicity testing. J. Appl. Toxicol. 2017, 37, 50-59. [CrossRef]

118. Di Lullo, E.; Kriegstein, A.R. The use of brain organoids to investigate neural development and disease. Nat. Rev. Neurosci. 2017, 18, 573-584. [CrossRef]

119. Velasco, S.; Kedaigle, A.J.; Simmons, S.K.; Nash, A.; Rocha, M.; Quadrato, G.; Paulsen, B.; Nguyen, L.; Adiconis, X.; Regev, A.; et al. Individual brain organoids reproducibly form cell diversity of the human cerebral cortex. Nature 2019, 570, 523-527. [CrossRef]

120. Qian, T.; Maguire, S.E.; Canfield, S.G.; Bao, X.; Olson, W.R.; Shusta, E.V.; Palecek, S.P. Directed differentiation of human pluripotent stem cells to blood-brain barrier endothelial cells. Sci. Adv. 2017, 3, e1701679. [CrossRef]

121. Li, R.A.; Keung, W.; Cashman, T.J.; Backeris, P.C.; Johnson, B.V.; Bardot, E.S.; Wong, A.O.T.; Chan, P.K.W.; Chan, C.W.Y.; Costa, K.D. Bioengineering an electro-mechanically functional miniature ventricular heart chamber from human pluripotent stem cells. Biomaterials 2018, 163, 116-127. [CrossRef]

122. Kulkeaw, K.; Tubsuwan, A.; Tongkrajang, N.; Whangviboonkij, N. Generation of human liver organoids from pluripotent stem cell-derived hepatic endoderms. PeerJ 2020, 8, e9968. [CrossRef]

123. Steichen, C.; Giraud, S.; Hauet, T. Kidney organoids. Med. Sci. 2019, 35, 470-477. [CrossRef]

124. Bonventre, J.V. Kidney organoids-a new tool for kidney therapeutic development. Kidney Int. 2018, 94, 1040-1042. [CrossRef] [PubMed]

125. Sirenko, O.; Hesley, J.; Rusyn, I.; Cromwell, E.F. High-content assays for hepatotoxicity using induced pluripotent stem cellderived cells. Assay Drug Dev. Technol. 2014, 12, 43-54. [CrossRef] [PubMed]

126. Mun, S.J.; Ryu, J.S.; Lee, M.O.; Son, Y.S.; Oh, S.J.; Cho, H.S.; Son, M.Y.; Kim, D.S.; Kim, S.J.; Yoo, H.J.; et al. Generation of expandable human pluripotent stem cell-derived hepatocyte-like liver organoids. J. Hepatol. 2019, 71, 970-985. [CrossRef] [PubMed]

127. Sirenko, O.; Grimm, F.A.; Ryan, K.R.; Iwata, Y.; Chiu, W.A.; Parham, F.; Wignall, J.A.; Anson, B.; Cromwell, E.F.; Behl, M.; et al. In vitro cardiotoxicity assessment of environmental chemicals using an organotypic human induced pluripotent stem cell-derived model. Toxicol. Appl. Pharmacol. 2017, 322, 60-74. [CrossRef]

128. Pointon, A.; Pilling, J.; Dorval, T.; Wang, Y.; Archer, C.; Pollard, C. From the Cover: High-Throughput Imaging of Cardiac Microtissues for the Assessment of Cardiac Contraction during Drug Discovery. Toxicol. Sci. 2017, 155, 444-457. [CrossRef]

129. McKeithan, W.L.; Savchenko, A.; Yu, M.S.; Cerignoli, F.; Bruyneel, A.A.N.; Price, J.H.; Colas, A.R.; Miller, E.W.; Cashman, J.R.; Mercola, M. An Automated Platform for Assessment of Congenital and Drug-Induced Arrhythmia with hiPSC-Derived Cardiomyocytes. Front. Physiol. 2017, 8, 766. [CrossRef]

130. Grimm, F.A.; Iwata, Y.; Sirenko, O.; Bittner, M.; Rusyn, I. High-Content Assay Multiplexing for Toxicity Screening in Induced Pluripotent Stem Cell-Derived Cardiomyocytes and Hepatocytes. Assay Drug Dev. Technol. 2015, 13, 529-546. [CrossRef]

131. Ni, X.; Yang, Z.Z.; Ye, L.Q.; Han, X.L.; Zhao, D.D.; Ding, F.Y.; Ding, N.; Wu, H.C.; Yu, M.; Xu, G.Y.; et al. Establishment of an in vitro safety assessment model for lipid-lowering drugs using same-origin human pluripotent stem cell-derived cardiomyocytes and endothelial cells. Acta Pharmacol. Sin. 2021, 1-11. [CrossRef]

132. Kandasamy, K.; Chuah, J.K.; Su, R.; Huang, P.; Eng, K.G.; Xiong, S.; Li, Y.; Chia, C.S.; Loo, L.H.; Zink, D. Prediction of drug-induced nephrotoxicity and injury mechanisms with human induced pluripotent stem cell-derived cells and machine learning methods. Sci. Rep. 2015, 5, 12337. [CrossRef]

133. Sherman, S.P.; Bang, A.G. High-throughput screen for compounds that modulate neurite growth of human induced pluripotent stem cell-derived neurons. Dis. Models. Mech. 2018, 11, dmm031906. [CrossRef]

134. Klaren, W.D.; Rusyn, I. High-Content Assay Multiplexing for Muscle Toxicity Screening in Human-Induced Pluripotent Stem Cell-Derived Skeletal Myoblasts. Assay Drug Dev. Technol. 2018, 16, 333-342. [CrossRef]

135. Chambers, S.M.; Fasano, C.A.; Papapetrou, E.P.; Tomishima, M.; Sadelain, M.; Studer, L. Highly efficient neural conversion of human ES and iPS cells by dual inhibition of SMAD signaling. Nat. Biotechnol. 2009, 27, 275-280. [CrossRef]

136. Karumbayaram, S.; Novitch, B.G.; Patterson, M.; Umbach, J.A.; Richter, L.; Lindgren, A.; Conway, A.E.; Clark, A.T.; Goldman, S.A.; Plath, K.; et al. Directed differentiation of human-induced pluripotent stem cells generates active motor neurons. Stem Cells 2009, 27, 806-811. [CrossRef]

137. Nguyen, H.X.; Nekanti, U.; Haus, D.L.; Funes, G.; Moreno, D.; Kamei, N.; Cummings, B.J.; Anderson, A.J. Induction of early neural precursors and derivation of tripotent neural stem cells from human pluripotent stem cells under xeno-free conditions. J. Comp. Neurol. 2014, 522, 2767-2783. [CrossRef] 
138. Lippmann, E.S.; Al-Ahmad, A.; Azarin, S.M.; Palecek, S.P.; Shusta, E.V. A retinoic acid-enhanced, multicellular human blood-brain barrier model derived from stem cell sources. Sci. Rep. 2014, 4, 4160. [CrossRef]

139. Klima, S.; Brüll, M.; Spreng, A.S.; Suciu, I.; Falt, T.; Schwamborn, J.C.; Waldmann, T.; Karreman, C.; Leist, M. A human stem cellderived test system for agents modifying neuronal $\mathrm{N}$-methyl-D-aspartate-type glutamate receptor $\mathrm{Ca}^{2+}$-signalling. Arch. Toxicol. 2021, 95, 1703-1722. [CrossRef]

140. PsychENCODE Consortium. Revealing the brain's molecular architecture. Science 2018, 362, 1262-1263. [CrossRef]

141. Lancaster, M.A.; Knoblich, J.A. Generation of cerebral organoids from human pluripotent stem cells. Nat. Protoc. 2014, 9, 2329-2340. [CrossRef]

142. Duong, A.; Evstratova, A.; Sivitilli, A.; Hernandez, J.J.; Gosio, J.; Wahedi, A.; Sondheimer, N.; Wrana, J.L.; Beaulieu, J.M.; Attisano, L.; et al. Characterization of mitochondrial health from human peripheral blood mononuclear cells to cerebral organoids derived from induced pluripotent stem cells. Sci. Rep. 2021, 11, 4523. [CrossRef]

143. Jameson, J.L.; Longo, D.L. Precision medicine-Personalized, problematic, and promising. N. Engl. J. Med. 2015, 372, 2229-2234. [CrossRef]

144. König, I.R.; Fuchs, O.; Hansen, G.; von Mutius, E.; Kopp, M.V. What is precision medicine? Eur. Respir. J. 2017, 50, 410-419. [CrossRef] [PubMed]

145. Kastrinos, F.; Samadder, N.J.; Burt, R.W. Use of Family History and Genetic Testing to Determine Risk of Colorectal Cancer. Gastroenterology 2020, 158, 389-403. [CrossRef] [PubMed]

146. Knabben, L.; Imboden, S.; Mueller, M.D. Genetic testing in ovarian cancer-Clinical impact and current practices. Horm. Mol. Biol. Clin. Investig. 2019, 41, 3. [CrossRef] [PubMed]

147. Tai, L.; Teoh, H.K.; Cheong, S.K. Reprogramming human dermal fibroblast into induced pluripotent stem cells using nonintegrative Sendai virus for transduction. Malays. J. Pathol. 2018, 40, 325-329. [PubMed]

148. Malik, N.; Rao, M.S. A review of the methods for human iPSC derivation. Methods Mol. Biol. 2013, 997, 23-33. [CrossRef] [PubMed]

149. Strikoudis, A.; Cieślak, A.; Loffredo, L.; Chen, Y.W.; Patel, N.; Saqi, A.; Lederer, D.J.; Snoeck, H.W. Modeling of Fibrotic Lung Disease Using 3D Organoids Derived from Human Pluripotent Stem Cells. Cell Rep. 2019, 27, 3709-3723. [CrossRef] [PubMed]

150. Kulkarni, S.; Rudnick, D.A. Induced Pluripotent Stem Cell-Derived Hepatocytes and Precision Medicine in Human Liver Disease. J. Pediatric. Gastroenterol. Nutr. 2018, 66, 716-719. [CrossRef]

151. Fermini, B.; Coyne, S.T.; Coyne, K.P. Clinical Trials in a Dish: A Perspective on the Coming Revolution in Drug Development. SLAS Discov. 2018, 23, 765-776. [CrossRef]

152. Fatkin, D. Familial dilated cardiomyopathy: Current challenges and future directions. Glob. Cardiol. Sci. Pract. 2012, 2012, 8. [CrossRef]

153. Tesson, F.; Saj, M.; Uvaize, M.M.; Nicolas, H.; Płoski, R.; Bilińska, Z. Lamin A/C mutations in dilated cardiomyopathy. Cardiol. J. 2014, 21, 331-342. [CrossRef]

154. Bidault, G.; Garcia, M.; Vantyghem, M.C.; Ducluzeau, P.H.; Morichon, R.; Thiyagarajah, K.; Moritz, S.; Capeau, J.; Vigouroux, C.; Béréziat, V. Lipodystrophy-linked LMNA p.R482W mutation induces clinical early atherosclerosis and in vitro endothelial dysfunction. Arterioscler. Thromb. Vasc. Biol. 2013, 33, 2162-2171. [CrossRef]

155. Sayed, N.; Liu, C.; Ameen, M.; Himmati, F.; Zhang, J.Z.; Khanamiri, S.; Moonen, J.R.; Wnorowski, A.; Cheng, L.; Rhee, J.W.; et al. Clinical trial in a dish using iPSCs shows lovastatin improves endothelial dysfunction and cellular cross-talk in LMNA cardiomyopathy. Sci. Transl. Med. 2020, 12, eaax9276. [CrossRef]

156. Han, D.; Wang, Y.; Wang, Y.; Dai, X.; Zhou, T.; Chen, J.; Tao, B.; Zhang, J.; Cao, F. The Tumor-Suppressive Human Circular RNA CircITCH Sponges miR-330-5p to Ameliorate Doxorubicin-Induced Cardiotoxicity Through Upregulating SIRT6, Survivin, and SERCA2a. Circ. Res. 2020, 127, e108-e125. [CrossRef]

157. Sharma, A.; Burridge, P.W.; McKeithan, W.L.; Serrano, R.; Shukla, P.; Sayed, N.; Churko, J.M.; Kitani, T.; Wu, H.; Holmström, A.; et al. High-throughput screening of tyrosine kinase inhibitor cardiotoxicity with human induced pluripotent stem cells. Sci. Transl. Med. 2017, 9, eaaf2584. [CrossRef]

158. Burnett, S.D.; Blanchette, A.D.; Grimm, F.A.; House, J.S.; Reif, D.M.; Wright, F.A.; Chiu, W.A.; Rusyn, I. Population-based toxicity screening in human induced pluripotent stem cell-derived cardiomyocytes. Toxicol. Appl. Pharmacol. 2019, 381, 114711. [CrossRef]

159. Stillitano, F.; Hansen, J.; Kong, C.W.; Karakikes, I.; Funck-Brentano, C.; Geng, L.; Scott, S.; Reynier, S.; Wu, M.; Valogne, Y.; et al. Modeling susceptibility to drug-induced long QT with a panel of subject-specific induced pluripotent stem cells. Elife 2017, 6, e19406. [CrossRef]

160. Shinozawa, T.; Nakamura, K.; Shoji, M.; Morita, M.; Kimura, M.; Furukawa, H.; Ueda, H.; Shiramoto, M.; Matsuguma, K.; Kaji, Y.; et al. Recapitulation of Clinical Individual Susceptibility to Drug-Induced QT Prolongation in Healthy Subjects Using iPSC-Derived Cardiomyocytes. Stem Cell Rep. 2017, 8, 226-234. [CrossRef]

161. Blinova, K.; Schocken, D.; Patel, D.; Daluwatte, C.; Vicente, J.; Wu, J.C.; Strauss, D.G. Clinical Trial in a Dish: Personalized Stem Cell-Derived Cardiomyocyte Assay Compared With Clinical Trial Results for Two QT-Prolonging Drugs. Clin. Transl. Sci. 2019, 12, 687-697. [CrossRef]

162. Zhang, M.; Sun, P.; Wang, Y.; Chen, J.; Lv, L.; Wei, W.; Jin, C.; Li, W. Generation of Self-Renewing Hepatoblasts From Human Embryonic Stem Cells by Chemical Approaches. Stem Cells Transl. Med. 2015, 4, 1275-1282. [CrossRef]

163. Raju, R.; Chau, D.; Cho, D.S.; Park, Y.; Verfaillie, C.M.; Hu, W.S. Cell Expansion During Directed Differentiation of Stem Cells Toward the Hepatic Lineage. Stem Cells Dev. 2017, 26, 274-284. [CrossRef] 
164. Wang, S.; Wang, X.; Tan, Z.; Su, Y.; Liu, J.; Chang, M.; Yan, F.; Chen, J.; Chen, T.; Li, C.; et al. Human ESC-derived expandable hepatic organoids enable therapeutic liver repopulation and pathophysiological modeling of alcoholic liver injury. Cell Res. 2019, 29, 1009-1026. [CrossRef]

165. Akbari, S.; Sevinç, G.G.; Ersoy, N.; Basak, O.; Kaplan, K.; Sevinç, K.; Ozel, E.; Sengun, B.; Enustun, E.; Ozcimen, B.; et al. Robust, Long-Term Culture of Endoderm-Derived Hepatic Organoids for Disease Modeling. Stem Cell Rep. 2019, 13, 627-641. [CrossRef]

166. Mun, S.J.; Hong, Y.H.; Ahn, H.S.; Ryu, J.S.; Chung, K.S.; Son, M.J. Long-Term Expansion of Functional Human Pluripotent Stem Cell-Derived Hepatic Organoids. Int. J. Stem Cells 2020, 13, 279-286. [CrossRef]

167. Volpato, V.; Webber, C. Addressing variability in iPSC-derived models of human disease: Guidelines to promote reproducibility. Dis. Models Mech. 2020, 13, dmm042317. [CrossRef]

168. Committee on Ethical, Legal, and Regulatory Issues Associated with Neural Chimeras and Organoids; Committee on Science, Technology, and Law; Policy and Global Affairs; National Academies of Sciences, Engineering, and Medicine. The National Academies Collection: Reports funded by National Institutes of Health. In The Emerging Field of Human Neural Organoids, Transplants, and Chimeras: Science, Ethics, and Governance; National Academies Press: Washington, DC, USA, 2021. [CrossRef] 